\title{
Trayectorias de intelectuales y redes culturales en la Amazonía peruana entre 1940 y 1980
}

\section{Trajectories of intellectuals and cultural networks in the Peruvian Amazon between 1940 and 1980}

\author{
Morgana Herrera \\ Kristel Best Urday \\ Yaneth Sucasaca
}

\section{Resumen}

La Amazonía es a menudo un punto ciego a la hora de definir una cultura nacional peruana, en particular, si se aborda desde la historia intelectual y literaria. Dentro del panteón de autores y pensadores que forman parte de lo que se ha definido como un canon intelectual peruano, aquellos que se presentan como amazónicos suelen estar ausentes. Sin embargo, varios han sido los intelectuales que han obrado para la difusión de su cultura desde la Amazonía. Este trabajo reúne tres estudios de las trayectorias y estrategias intelectuales de tres autores amazónicos: Francisco Izquierdo Ríos, Javier Dávila Durand y Arnaldo Panaifo Teixeira.

Palabras clave: Amazonía peruana, Francisco Izquierdo Ríos, Javier Dávila Durand, Arnaldo Panaifo Teixeira, Intelectuales de la Amazonía 


\section{Abstract}

The Amazon is often a blind spot when defining a Peruvian national culture, particularly from an intellectual and literary history perspective. Within the pantheon of authors and thinkers who are part of what has been defined as a Peruvian intellectual canon, those who define themselves as Amazonians are usually absent from it. However, several intellectuals have worked for the dissemination of their culture from the Amazon. This work brings together three studies of intellectual trajectories and strategies of three Amazonian authors: Francisco Izquierdo Ríos, Javier Dávila Durand and Arnaldo Panaifo Teixeira.

Key words: Peruvian Amazon, Francisco Izquierdo Ríos, Javier Dávila Durand, Arnaldo Panaifo Teixeira, Amazonian intellectuals.

\section{Introducción}

Dentro del panteón de autores y pensadores que forman parte de lo que se ha definido como un canon intelectual peruano, aquellos que se definen como amazónicos y cuya obra está particularmente impregnada de problemáticas vernáculas de la selva, suelen estar ausentes de este o son figuras olvidadas. Sin embargo, varios autores han obrado para difundir la cultura amazónica o han generado en las ciudades amazónicas un dinamismo intelectual productor de actividades culturales que merecen ser estudiadas y rescatadas. Ante la ausencia de instituciones estatales culturales fuertes en este 
territorio marginalizado del Perú, son iniciativas individuales o de grupos de individuos las que han prevalecido y han generado tensiones o alterado una cultura peruana hegemónica. Las estrategias desplegadas para generar este dinamismo cultural pueden ser las habituales, como crear un grupo de escritores, fundar una revista, formar un corpus de textos, publicar manifiestos, etc. Sin embargo, realizar estas tareas que son características del quehacer intelectual desde la periferia implica una serie de dificultades y desafíos. Uno de ellos es hacer oír su voz, un elemento esencial de la definición del intelectual que es ante todo un personaje público y portavoz de problemáticas sociales, políticas y culturales. Hacemos nuestro el análisis que hace Germán Albuquerque del intelectual como "aquel individuo perteneciente al ámbito de la ciencia, del arte, del pensamiento o de la cultura que se dedica a pensar, comprender y explicar la sociedad en que vive, debiendo transmitir el resultado de su reflexión a un público determinado" (2011, p. 9).

Ahora bien, la cuestión de la transmisión es tanto más difícil en un espacio alejado de los centros de poder y de redes culturales como lo es la Amazonía. Así pues, los individuos que consiguen fomentar una ebullición intelectual que sobrepase una escala meramente local suelen venir de los núcleos urbanos, donde existe un entramado cultural sobre el cual se pueden apoyar. Además, nos basamos en una historiografía latinoamericanista que amplía la noción del intelectual en el sentido hegemónico europeo y que integra a agentes culturales, como maestros, impresores, editores, periodistas, etc. Flavia Fiorucci y Laura Graciela Rodríguez desarrollan la noción del intelectual y afirman que "No hay que pensar únicamente en los 'grandes creadores de doctrinas', como nos advierte Altamirano (2006) sino también 'en un conjunto 
más amplio de profesiones intelectuales y de operadores del mensaje ideológico, desde los profesores a los periodistas'”. (2018, p. 9).

En este trabajo, se estudia la construcción de prácticas y de redes intelectuales a la luz de la trayectoria y las obras de tres escritores que por sus actividades generaron un dinamismo cultural en la Amazonía peruana, más precisamente, en la ciudad de Iquitos. A su vez, estos tres escritores revelan tres momentos históricos distintos del Perú respecto a la selva amazónica y el contexto en el que se desenvuelven tiene consecuencias sobre la formación de sus proyectos y los obstáculos o apoyos que encontraron para realizarlos. Morgana Herrera estudia la figura de Francisco Izquierdo Ríos en un contexto de nacionalismo y de formación de un folklore peruano en los años cuarenta. Kristel Urday Best se acerca a Javier Dávila Durand en las décadas de 1960 y 1970, en un momento en que el Estado peruano desarrollaba un proyecto modernizador basado en el trazado de carreteras y en la explotación petrolera y maderera. En ese contexto, surgieron nuevas iniciativas grupales basadas en un espíritu revolucionario y cuestionador, que generó redes de amistades creativas. Por último, Yaneth Sucasaca se interesa en el caso de Arnaldo Panaifo Teixeira y en su actividad literaria y editorial en las décadas de 1980 y 1990, particularmente críticas para

188 el devenir del Perú y la Amazonía.

Dada la mencionada carencia de instituciones oficiales culturales en la Amazonía, hemos recurrido a bibliotecas privadas o a una de las pocas instituciones centralizadoras, como es el Centro de Estudios Teológicos de la Amazonía (CETA) y su Biblioteca Amazónica que atesora una importante colección de publicaciones periódicas que permiten reconstruir la esce- 
na cultural, social y política urbana de Iquitos y de su región. Por otro lado, los archivos particulares de los propios escritores y de sus descendientes revelan diversos aspectos de su quehacer, que se caracteriza por una labor múltiple, versátil y compleja. Los archivos particulares nos permiten analizar su creación literaria a partir de un lente amplio y múltiple. Por un lado, nos aproximamos a la materialidad de su creación (escrito a máquina o a mano, correcciones, diversas versiones, papel reutilizado, etc.), a lo que se decidió conservar y cuidar, y a lo que se dejó inconcluso, en proceso o en proyecto. 



\title{
Francisco Izquierdo Ríos: El paso de una cultura amazónica regional a la escala nacional
}

\author{
Francisco Izquierdo Ríos: The transition from a \\ regional Amazonian culture to a national scale
}

Morgana Herrera ${ }^{1}$

Universidad de Toulouse Jean Jaurès

Para acercarnos a la práctica intelectual de Francisco Izquierdo Ríos, señalaré algunos datos de la vida del autor. Mi propósito no es elaborar una biografía, sino destacar hitos de su trayectoria que expliquen o señalen el compromiso que tuvo de difundir su visión de la cultura amazónica. Izquierdo Ríos nació en 1910, en Saposoa, en la provincia del Huallaga, departamento de San Martín. Tanto su fecha como lugar de nacimiento hacen de él un hombre del límite, ${ }^{2}$ sea este temporal o geográfico. Nació en los últimos años del auge cauchero, un periodo de menor dinamismo económico en la Amazonía y en la región de la selva alta, entre la cordillera andina y el llano amazónico. Esta situación del entredós es

1 Doctoranda y docente del departamento de estudios hispánicos e hispanoamericanos de la Universidad de Toulouse Jean Jaurès.

Contacto: morgana.herrera@univ-tlse2.fr

2 Entiendo esta palabra en el sentido que le da Mabel Moraña en La escritura del limite retomando a autores como Homi Bhabha para designar a agentes que se sitúan en un entredós, en la porosidad de la frontera que no separa, sino que es el espacio de lo colindante. 
patente en él y en su afán de borrar la falsa frontera entre sierra y selva impuesta por el imaginario colectivo peruano. ${ }^{3} \mathrm{~A}$ pesar del decaimiento económico poscauchero y de venir de un pueblo y de una familia humilde, las huellas de un pasado más rico en la región todavía estaban presentes en el sistema educativo que le permitió realizar estudios. Tras su secundaria en el colegio nacional de la capital del departamento, Moyobamba, estudió en el Instituto Nacional Pedagógico de Lima y se graduó como normalista en 1931. Empezó su vida de maestro, que nutrió en gran medida su obra, tanto ficcional como de recopilaciones de la tradición oral. Recorrió varios pueblos de San Martín y de Amazonas y en cada lugar donde fue profesor fundó una nueva revista, lo que muestra su voluntad de reunir a las pequeñas élites de intelectuales locales, a menudo los maestros, en torno a un proyecto editorial. Es el caso del órgano de los centros escolares de Luya, El Luyano fundado en 1933; Curibamba fundado en 1937 en Bongará, y Remo fundado en Yurimaguas en 1940. ${ }^{4}$ Sin duda, su mayor realización en ese terreno fue la revista Trocha creada en 1941 cuando llegó a Iquitos como inspector de enseñanza. Trocha marcó un giro en su carrera, ya que fue publicada durante los años del cuarto centenario del descubrimiento del río Amazonas, por lo que tuvo mayores medios de difusión, dado el interés estatal en promocionar inicia-

3 Buen ejemplo de ello es su primera publicación Ande y selva de 1939, que combina cuentos y tradiciones de ambas regiones. Para un estudio más profundo, véase Cornejo Chaparro (2013).

4 Es casi imposible encontrar estas revistas hoy en día. Lo poco que sabemos de ellas proviene de menciones que hace Francisco Izquierdo Ríos en entrevistas o de los escasos números que se conservan en el archivo familiar. 
tivas culturales de la Amazonía. Empezó luego la segunda etapa de su vida marcada por su colaboración con diversas instituciones oficiales de Lima, en las que desempeñó cargos variados: fue jefe de la sección de folklore y artes populares cuando esta se fundó en el Ministerio de Educación Pública, donde trabajaba como jefe de informaciones desde 1943; fue jefe de publicaciones de la recién fundada Casa de la Cultura del Perú en 1963 y siguió ejerciendo ese cargo cuando dicha institución pasó a ser el Instituto Nacional de Cultura (INC) en 1971. En los dos últimos años de su vida fue presidente de la Asociación Nacional de Escritores y Artistas (ANEA) antes de morir en 1981. Durante ese periodo limeño siguió contribuyendo en la difusión de lo amazónico, sea por su labor como editor -en particular cuando dirigió la revista Cultura y Pueblo-, como periodista, ${ }^{6}$ como novelista o cuentista. Me acercaré a la práctica intelectual de este personaje multifacético y tan poco estudiado centrándome, por falta de espacio, únicamente en dos proyectos que dan cuenta cabal del papel fundamental de Francisco Izquierdo Ríos como agente de difusión de cierta cultura amazónica. ${ }^{7}$ Estos dos hitos son su

5 En un próximo número de la revista Caravelle, se publicará un artículo mío titulado "La revista Trocha (1941-1944) y la constitución de una intelectualidad amazónica peruana”, en el que ahondo el estudio de la revista.

6 Me ha sido imposible rastrear toda su producción en la prensa nacional, pero se sabe que Francisco Izquierdo Ríos tuvo a inicios de la década de 1950 una crónica en El Comercio llamada "En el país de los árboles" y en 1980 otra crónica de temas amazónicos en el diario Expreso titulada "Mirador de la selva".

7 Matizo la noción de "cultura amazónica" en la medida que Francisco Izquierdo Ríos difunde la cultura que él conoce, es decir, tradiciones y literatura fundamentalmente mestizas y oriundas de las zonas que recorrió del departamento de San Martín y Amazonas y, en menor medida, de Loreto. Él mismo reconoce en Pueblo y bosque su conocimiento limitado de la Amazonía. 
papel de animador cultural en Iquitos en torno a la revista Trocha y su labor como introductor de lo amazónico en la elaboración de un folklore nacional. Estos dos proyectos demuestran el compromiso intelectual de Izquierdo Ríos de aportar el elemento amazónico a toda empresa de constitución y consolidación de la cultura peruana.

\section{Consolidación de un polo intelectual en Iquitos: acerca de la revista Trocha}

Después de su regreso a Lima, tras finalizar un puesto de maestro en Yurimaguas, Francisco Izquierdo Ríos fue reclamado como inspector de educación en Iquitos por los dos senadores de Loreto, Ernesto Montagne y Oscar Mávila. La razón de este pedido es que ambos senadores consideraron a Izquierdo Ríos "como hombre necesario para ese ambiente con ocasión del IV Centenario de Descubrimiento del Río Amazonas" (Izquierdo Ríos, 1941). El tetracentenario del descubrimiento del río Amazonas que celebra la expedición de Francisco de Orellana de 1542 coincidió con el conflicto con Ecuador en las fronteras amazónicas y con la firma del Tratado de Límites de Río de Janeiro a favor de la posición peruana. Se desplegó, así, de 1941 hasta 1943 un dinamismo sin precedente por parte del Estado a favor de la visibilización de la Ama-

194 zonía y la difusión de discursos acerca de este espacio, sean estos científicos, políticos o literarios. ${ }^{8}$ En ese sentido, Izquierdo Ríos fue presentado como el hombre ideal

8 He desarrollado el estudio de este centenario en "La construcción de la peruanidad de la Amazonía: el caso del IV Centenario del Descubrimiento del Río Amazonas de 1942", RIRA, 3 (2), 121-169 (octubre 2018). 
para dinamizar el esfuerzo conmemorativo en Iquitos. El maestro no se limitó a organizar un jubileo coyuntural, sino que dejó su huella en el escenario cultural iquiteño, a pesar de la brevedad de su estadía, gracias al proyecto de Trocha. Esta publicación, sin duda, estuvo inspirada por las experiencias previas de revistas que había fundado. Varias ideas que se pueden leer en las editoriales de sus primeros experimentos se vuelven a encontrar en Trocha. Órgano mensual del magisterio del Bajo Amazonas. Para citar un ejemplo, en el primer editorial de Remo se afirma: "Creemos nosotros que en el Perú debe haberse una labor estrictamente regional, debe pues empezarse por interpretar 'nuestras realidades regionales' para luego poder conocer las del país todo. [...]. Ya es tiempo de que Perú se conozca a sí mismo" (Remo, 1940, p. 1) (El destacado es mío). La idea de que es hora de dar a conocer la selva para conocer todo el Perú es la que estructura el proyecto de Trocha y la mayoría de los proyectos posteriores de Izquierdo Ríos. Desde el primer número de Trocha del 30 de setiembre de 1941, la revista dejó claro su objetivo de reunir a autores comprometidos con problemáticas regionales a través de la siguiente interpelación que aparece a manera de anuncio en todos los números: "Intelectual o profesional de la selva: colabora en 'Trocha', la revista que recoge la inquietud de toda la Hoya Amazónica”. Más allá de reunir escritos específicamente dirigidos a los maestros de la región -como artículos críticos sobre los bajos sueldos del magisterio en una zona donde la carestía de vida es extremadamente elevada- la publicación funcionó efectivamente como un núcleo alrededor del cual giraron intelectuales en ciernes y más confirmados de todo Lore- 
to. Fue una plataforma literaria para jóvenes poetas 9 que encontraron la oportunidad de publicar cuando la industria editorial en la Amazonía era casi inexistente. La revista, en particular el número especial de febrero de 1942 para el cuarto centenario del descubrimiento del río Amazonas, cumplió el rol de memoria de la literatura amazónica. El número es citado hasta hoy por investigadores de la literatura, ${ }^{10}$ como el garante del rescate de poetas de la segunda mitad del siglo XIX que celebraron el río Amazonas, como Juan Fabriciano Hernández, quien compuso en 1868 su Canto al Amazonas o Antonio del Carmen Sotelo y su Canto al Amazonas de 1888. Además de estos dos autores de Chachapoyas y Moyobamba, respectivamente, Francisco Izquierdo Ríos publicó también al poeta limeño Carlos Amézaga y su conocido Canto al Amazonas, "pues se encuentra inserto hasta en los libros de lectura para escolares. Quién no recuerda los fáciles versos: Hay un rio, monarca de los ríos, etc.” (1942, p. 56). Incluir en una revista editada en Iquitos a poetas originarios de la selva alta y de la capital permite dar cuenta de un proceso histórico, el del súbito interés suscitado por Loreto en el boom del caucho. La zona de mayor producción cauchera atrajo masivamente a migrantes de todo el Perú, especialmente de las cercanas regiones de Amazonas y Moyobamba. Además, la publicación de este patrimonio poético fue pensada como un incentivo a la creación poética, como indica la maquetación de la sección

9 El incentivo que generó Trocha fue tal en estos jóvenes autores, que varias periodizaciones de literatura amazónica hablan del grupo Trocha en la década de los años cuarenta. Véase, por ejemplo, Marticorena (2009). Algunos de los autores de este grupo son Julio G. Vergara, Felipe R. Documet y Julio de Pena y Piña.

10 Pienso en Manuel Marticorena y en Ana Molina Campodónico, por ejemplo. 
“Los poetas y el río Amazonas", que no solo cuenta con los poetas citados, sino también con un poema contemporáneo de Izquierdo Ríos titulado La leyenda de "El Dorado" y una marcha compuesta para el tetracentenario por Anita Edery con letra de Emilia Barcia Boniffatti. La presencia de Emilia Barcia en la revista es un hecho clave para entender otro aporte fundamental de Trocha: crear una red para congregar una élite intelectual local. Efectivamente, la coherencia editorial de la revista le cede a veces el paso a una prioridad mayor, la de incluir a todas las plumas del Loreto de esta década de los cuarenta. Uno de los principales rasgos de toda revista es ser una creación colectiva, lo que se verifica en Trocha, que se convirtió también en pretexto para seleccionar y reunir a aquellos considerados como los pensadores más destacados de la Amazonía. Por ejemplo, Emilia Barcia Boniffatti, delegada por Loreto de la Asociación Nacional de Maestros y conocida como la instauradora de los primeros jardines de la infancia en el Perú, volvió a su Iquitos natal durante el tetracenterario y publicó en Trocha las charlas que realizó para la ocasión.

Asimismo, se incluyeron largos artículos de Luis Navarro Cáuper, periodista de uno de los principales periódicos regionales, El Oriente, y figura central del mundo intelectual iquiteño, a pesar de que sus temas y la extensión de sus artículos difieren del resto de la revista como se ve, por ejemplo, en El atletismo en la historia y su importancia en los deportes del número 8. Del mismo modo, se publicaron escritos del reconocido médico Maxime Kuczynski-Godard, que si bien tienen una aplicación directa para los maestros de escuela cuando aborda cuestiones de educación de higiene, se encuentran en la revista, sobre todo, gracias a la fama del médico director del leprosario San Pablo. Varios años des- 
pués, al reflexionar sobre la experiencia de Trocha, Francisco Izquierdo Ríos escribió: "Logré que el doctor Kuczynski colaborara en la revista "Trocha" (1975, p. 294) (el destacado es mío). Izquierdo Ríos no solo se limitó a gestionar esta publicación, sino que participó activamente en varias iniciativas culturales impulsadas por la conmemoración del descubrimiento de Orellana: inauguró Radio Loreto y organizó la exposición amazónica de los maestros. Así lo podemos leer en el discurso de Emilia Barcia en honor a las actividades del cuarto centenario:

(...) tampoco podemos olvidar que la iniciativa y la culminación de esta idea, ha tenido por suerte, un magnífico dirigente en el Inspector de Instrucción Sr. Francisco Izquierdo: maestro de reconocidos méritos en toda la República, maestro cuya pluma ha hecho llegar hasta la capital y hasta el despacho del Sr Ministro de Educación las realidades educacionales de esta región. Admirador de nuestra Selva; su emoción literaria hace que en los diarios de más difusión del Perú y de América, sea Loreto, conocido como la tierra promisora de El DORADO. Para maestros y para niños, ha sido una suerte el tener como Inspector a Izquierdo, y ha sido uno de los grandes aciertos del Despacho de Instrucción el destinarlo a Iquitos (1942, p. 29).

Como lo descubrimos en el correo de lectores, la revista llegó efectivamente a tener cierta difusión en la capital, lo cual motivó el nacimiento de una amistad entre el novelista Arturo Hernández, loretano radicado en Lima, y Francisco Izquierdo Ríos. Hernández felicita en una carta al director de Trocha por su iniciativa, le agradece la publicación de una crítica positiva de su novela Sangama y se sitúa en la misma dinámica: "Sangama como usted lo sabe, es un esfuerzo para dar a conocer nuestra montaña tan menospreciada hasta hoy en que creo que se inicia una nueva era para ella" (1942). La revista 
acabó poco tiempo después del nombramiento de Francisco Izquierdo Ríos a Lima en el Ministerio de Educación, ${ }^{11}$ pero no dejó de ser recordada en el paisaje intelectual de Iquitos de los años cuarenta. Inspiró inclusive una iniciativa similar al hermano de Francisco Izquierdo Ríos, Guillermo, maestro y antiguo colaborador de la revista, para reanudar con esta labor en la provincia de San Martín. La primera edición de Trocha. Revista Mensual del Magisterio de la provincia de San Martín salió en Tarapoto en abril de 1957. La revista era una prolongación de la iniciativa loretana, como se indica en un artículo al comentar sobre el título que "corresponde a una revista que en los años de 1941 a 1945 se editó en esta ciudad [de Iquitos] bajo la égida del conocido escritor don Francisco Izquierdo Ríos, secundado por la élite de la intelectualidad loretana representada por el cuerpo magisterial" (Westman, 1957 , p. 3). Este juicio del proyecto loretano de Izquierdo Ríos escrito más de una década después confirma la estela de ebullición cultural que dejó la revista en la región amazónica.

\section{Integración de lo amazónico al folklore nacional: la publicación de Mitos, leyendas y cuentos peruanos}

Una segunda etapa importante dentro de la trayectoria intelectual de Francisco Izquierdo Ríos es su papel en la formación de un folklore amazónico que pueda ser integrado en los proyectos de constitución de un folklore peruano. ${ }^{12}$

11 Si bien no he conseguido encontrar una colección completa de Trocha, se sabe que a partir del número 16 Francisco Izquierdo Ríos ya no participaba en la redacción de la publicación y que el último número se publicó probablemente en 1945 con menos páginas que la primera edición.

12 No volveré sobre las diferentes definiciones de la palabra "folklore" acuñada a mediados del siglo XIX por el británico William Thoms. La 
Cabe recordar que la década de 1940 es particularmente rica en iniciativas y reflexiones sobre este tema. Algunos ejemplos de este nuevo dinamismo son la fundación en 1941 de la primera revista peruana de folklore, Waman Puma en Cusco, seguida el año siguiente por la revista limeña Folklore. Tribuna del Pensamiento Peruano, la creación de la cátedra de Folklore, Lenguas Indígenas y Arqueología en la Universidad Nacional del Cusco en 1943, la creación del Museo de la Cultura Peruana en Lima en 1946, dirigido por Luis E. Valcárcel y la apertura de la Escuela de Música y Danzas Folklóricas en 1948. Todos estos proyectos tendieron a equiparar lo folklórico con la identidad nacional y pocos son los proyectos de esta lista que abarcaron la Amazonía dentro de lo que se estaba definiendo como una cultura peruana oficinal. En ese contexto, Francisco Izquierdo Ríos impulsó lo amazónico en la esfera nacional, se centró en la literatura de tradición oral y recalcó su riqueza. ${ }^{13} \mathrm{La}$ experiencia de

considero en el sentido que se le daba en el contexto histórico que me interesa, es decir, en el sentido de sabiduría popular transmitida por vías no escritas o no institucionales y el estudio de dicho material. José María Arguedas resume esta idea en su artículo “¿Qué es el folklore?” en el primer número de la revista Cultura y Pueblo de enero-marzo de 1964 y agrega que, a diferencia de Europa, donde el folklore es considerado cultura de las minorías, en el Perú se trata de la cultura de las mayorías.

13 Izquierdo Ríos tiene una concepción bastante limitada de lo que considera folklore de la selva; si bien insiste en el hecho de que pocas regiones generan tal cantidad de historias, invoca a menudo una tradición de baile y de música mucho menos rica que las otras regiones del Perú. Irónicamente, lo señala en un artículo titulado "Música y bailes folklóricos de la selva" del único número de la revista Trocha que fundó en Lima en 1951: "La selva no posee la riqueza de música y bailes folklóricos de la región de la sierra, por ejemplo. Las razones son obvias. En la selva no se ha producido el fenómeno de aculturación con la intensidad con que ha tenido lugar a través de los siglos en la sierra. [...] Casi es imposible poder 
recopilación de mitos y leyendas vernáculas realizada gracias a los maestros de las escuelas rurales del Bajo Amazonas que habían alimentado las páginas de Trocha, le sirvió a Izquierdo Ríos para llevar a cabo este proyecto a una escala nacional. El inspector de enseñanza regresó a Lima en 1943 cuando fue llamado a trabajar en el Ministerio de Educación Pública. Al fundarse en ese ministerio la sección de folklore, Izquierdo Ríos fue despachado a ella para construir sus bases. Es así como participó en el proyecto de mayor contribución a la constitución de un folklore nacional en el ámbito literario: la publicación de Mitos, leyendas y cuentos peruanos en 1947. ${ }^{14}$ Esta obra compendia relatos provenientes de la costa (20 leyendas), de la sierra ( 2 mitos, 51 leyendas y 8 cuentos) y de la selva (16 leyendas y 22 cuentos), según la habitual tripartición esquemática de la geografía del país que sigue el libro. La división entre mito, leyenda y cuento no es definida por los editores y la tipificación de cada relato resulta algo artificial. Según el testimonio de Izquierdo Ríos, ${ }^{15}$ el trabajo de compilación se hizo con el apoyo de los maestros de escuela por falta de medios del Estado. Tras una capacitación en Lima sobre métodos para recoger relatos, se encargó la la-

señalar una música típica de la selva, a excepción, desde luego, aunque también pobre, de la de los indios salvajes, asunto que corresponde al campo etnológico" (p. 3).

14 Desde su primera edición, la obra de Arguedas e Izquierdo Ríos, si bien es criticada y criticable por cierta falta de rigurosidad científica en la técnica de recopilación, sigue siendo un clásico de la literatura peruana que cuenta con varias reediciones. A nivel internacional, es reconocida como quizás la más representativa de la tradición peruana, como lo muestra la edición de 2009 y reedición en 2014 por la editorial madrileña Siruela, en su colección Biblioteca de Cuentos Populares.

15 Izquierdo Ríos menciona en diversas ocasiones cómo se realizó esta obra, pero su testimonio más completo se encuentra en Pueblo y bosque. 
bor de recolectar este material a maestros de las tres regiones mencionadas. Si insiste en el motivo económico como razón de este proceder, añade que se justifica también por la situación misma del maestro que "por la índole de su trabajo y por nuestra peculiar realidad geográfica, se halla identificado con el pueblo, y por lo tanto en condición de conocer mejor sus manifestaciones. Además, por la necesidad que siente en su escuela de una literatura infantil a base de temas peruanos, es impulsado a recoger expresiones populares [...] para utilizarlas en dicho propósito" (Izquierdo Ríos, 1964). Hacer de los maestros los únicos recopiladores de folklore literario restringe de antemano la selección al "recoger el material folklórico de la región en donde funciona la escuela" (Folklore, 1943, p. 1).

Si el trabajo de selección y de edición fue realizado en colaboración con José María Arguedas, quien firmó el prólogo, ${ }^{16}$ Francisco Izquierdo Ríos eludió varias veces la participación de su insigne colaborador y recalcó sobre todo su propio papel y el de los recopiladores: "En mi gestión [en el Ministerio de Educación] recogí el folklore literario de mi país con la participación de maestros y alumnos de toda la república.

16 Irónicamente comenta en Pueblo y bosque: "Las consideraciones acerca del contenido del libro no debían llevar la firma de Arguedas ni de Izquierdo Ríos por razones obvias; pero insólitamente, aparecen las iniciales de Arguedas...” (p. 312). Sin querer entrar en el debate, Arguedas ya había sufrido para esa época varios episodios de surménage y habla de su período en el ministerio como de una época de trabajo arduo. En una carta a su hermano Arístides del 30 de setiembre 1946 escribe: "A fin de año se publicará un volumen de cuentos y leyendas, con fines didácticos y de investigación. Pero desde aquellos años que me quemé en el ministerio, mi capacidad de trabajo se ha quedado reducida a una tercera parte" (Pinilla, 1999, pp.202-203). 
Fue un lindo trabajo. De allí salió Mitos, leyendas y cuentos peruanos" (El Diario de Marka, 1980). En otra entrevista, menciona a Arguedas como colaborador del trabajo, pero únicamente para minimizar su rol: "Yo era jefe de la Sección de Folklore y Artes Populares y él, Conservador General de Folklore. Llegó Arguedas a mi oficina, cuando ya estábamos terminando la recopilación de folklore literario del país por medio de los maestros y alumnos de la República. Entonces colaboró conmigo en la composición del libro" (Estampa, Revista de Expreso, 1972).

No duda, sin embargo, en reconocer que su encuentro y su amistad en Lima con otros reconocidos intelectuales peruanistas como Luis E. Valcárcel y Jorge Basadre fueron incentivos para participar desde su conocimiento de la Amazonía a una idea global de formación de un patrimonio literario peruano. Coincide con Basadre en el Ministerio de Educación cuando este era ministro y declara al respecto: "Fue sin duda, uno de los pocos hombres excepcionales que surgen de tiempo en tiempo. De igual forma, resalta la figura luminosa de Luis Valcárcel, a quien consideró también como otro forjador de peruanidad" (El Diario de Marka, 1980). Fuera de las probables tensiones que generó la corresponsabilidad con Arguedas en este proyecto editorial, está claro que la parte llamada "Selva" de Mitos, leyendas y cuentos peruanos estaba bajo la responsabilidad de Izquierdo Ríos. ${ }^{17}$ En efecto, varios recopiladores de los cuentos y de las leyendas de esta región

17 Es muy probable que los relatos recogidos en el departamento de Amazonas, limítrofe de los Andes y de la selva, y los relatos clasificados en la parte "Sierra" sean también el resultado de los contactos de Izquierdo Ríos, ya que todos los informantes provienen de Bongará, donde había ejercido como maestro. 
mencionados por la obra son antiguos colaboradores de Trocha, ${ }^{18}$ cuando no son directamente miembros de su familia. ${ }^{19}$ Por otro lado, todos son profesores de escuelas situadas en los departamentos selváticos de San Martín y de Loreto. ${ }^{20}$ La ausencia de relatos proveniente de Madre de Dios es de hecho muy reveladora de la gestión de Francisco Izquierdo Ríos, como lo escribirá años después en Pueblo y bosque, su desconocimiento de Madre de Dios y su falta de contactos con informantes en ese departamento de la Amazonía del sur peruano tuvo como consecuencia la ausencia de material folclórico de la región en sus publicaciones. Además, en la mayoría de sus estudios folklóricos posteriores se nota claramente la filiación con la recopilación de 1947, ya que reutiliza ese material. ${ }^{21}$ Con esta dinámica de citar sus trabajos antiguos, pero callando la referencia explícita, Izquierdo Ríos consolidó de manera cada vez más definitiva y siempre bajo su control lo que se estaba construyendo como folklore literario de la selva. Además, el acto de repetir es la condición necesaria de la "invención de la tradición", como lo señala Eric Hobsbawm (Hobsbawm y Ranger, 2012) e Izquierdo Ríos estaba “inventando" una literatura amazónica peruana, en el sentido de institucionalizarla como tradición nacional. El control de Izquierdo Ríos sobre los relatos amazónicos en

18 Es el caso de Julio G. Vergara o Juan Daniel del Águila

19 Es el caso de sus hermanas Irene y Cecilia Izquierdo Ríos, preceptoras en Saposoa y Moyobamba, respectivamente, y de su hermano Guillermo, quien también había colaborado en Trocha.

20 En esa fecha, el actual departamento de Ucayali no había sido creado y formaba parte de Loreto.

21 Véase, por ejemplo, su artículo Folklore peruano. Relatos populares de la Selva. Sus fuentes. Revista Peruana de Cultura, junio 1963, I, nº 1, pp. 142-166. 
Mitos, leyendas y cuentos peruanos se encuentra en la sección de "notas" al final del libro. La cantidad de las que ahondan o definen palabras de los relatos es mucho mayor para la parte de la selva. ${ }^{22}$ El conjunto de estas notas está a cargo oficialmente de los dos compiladores y esta atención desproporcionada a la parte amazónica nos informa sobre dos aspectos: primero, que la realidad natural, geográfica y lingüística de la selva es mucho menos evidente para el primer público de esta publicación -los escolares y los maestros-, y segundo, que Izquierdo Ríos tiene interés en utilizar todo el espacio editorial posible para difundir sus saberes vernáculos.

Mitos leyendas y cuentos peruanos es un parteaguas en cuanto a la difusión a escala nacional de relatos tradicionales de la Amazonía. Según el propio Izquierdo Ríos, "patentiza, por primera vez, una expresión integral del alma de nuestro pueblo, a la par que un encomiable esfuerzo colectivo. Y con la presencia de la Selva también por primera vez en un libro de este carácter" (1975, p. 312). Está claro que el autor se autocongratula de esta compilación, sobre todo, teniendo en cuenta que la vuelve a editar en 1970, cuando fue jefe de publicaciones de la Casa de la Cultura del Perú. Sin embargo, el juicio de Izquierdo Ríos sobre la importancia de esta obra es fundamentado. En efecto, antes de 1947, pocas fueron las publicaciones que recopilaran y, sobre todo, que difundieran relatos de la Amazonía. Izquierdo Ríos ya había publicado por lo menos dos obras de difusión de la tradición oral peruana amazónica, Ande y selva en 1939 y Tierras del alba en $1946 .{ }^{23}$ Se trata, sin embargo, de obras de su autoría

22 De las 66 notas, 42 se refieren a cuentos y leyendas de la selva.

23 Además, la primera vez que la revista Folklore. Tribuna del Pensamiento Peruano publicó un texto de tema amazónico, fueron dos poemas de 
en las que, si bien reconoce la base tradicional de sus relatos, no los presenta como una recopilación de material folklórico. En las bibliografías de Raúl Porras Barrenechea y de Federico Schwab publicadas a inicios de la década de los cuarenta ${ }^{24} \mathrm{o}$ en la bibliografía específicamente sobre mitología amazónica de Ana María Espinola Carranza y Miguel Ángel Rodríguez Rea publicada en el tercer número de Amazonía peruana en 1978, pocas son las publicaciones que salen del ámbito de especialistas. La mayoría de mitos o leyendas que tienen una entrada en esos estudios se publicaron mayoritariamente en boletines de instituciones científicas o religiosas como la $R e$ vista del Museo Nacional o Misiones Dominicanas del Perú, o en libros de carácter antropológico que a veces incluyen mitos, únicamente con el fin de estudiar un pueblo indígena. ${ }^{25}$ Fuera de publicaciones en revistas especializadas o que tengan visos claramente científicos, varios libros de mitos y leyendas de la Amazonía preceden el trabajo de Arguedas e Izquierdo Ríos. Pienso en las pioneras Leyendas y tradiciones de Loreto de Jenaro Herrera publicada en Iquitos en 1918 y en Doce novelas de la selva de Emilio Romero publicada en Lima en 1934, también en las publicaciones del Comité del IV Centenario del Descubrimiento del Río Amazonas, como Ayahuasca. Mitos y leyendas del Amazonas de Arturo

Francisco Izquierdo Ríos titulados "La tarrafa” en referencia a la principal herramienta de los pescadores ribereńos de la Amazonía y "El manguaré", tambor tradicional de varios pueblos nativos de la selva (año II, número IV, Lima, marzo 1943.)

24 Se trata de Raúl Porras Barrenechea, "Esquema para una bibliografía amazónica”. En Mercurio Peruano, año XVII, número180, pp. 159-167 y de Federico Schwab, Bibliografía etnológica de la Amazonia peruana, 1542-1942. Lima, Compañía de impresiones y publicidad, 1942.

25 Es el caso de Los machiguengas de Fray Vicente de Cenitagoya o El hombre del Amazonas de Juan E. Coriat. 
Burga Freitas en 1941, ${ }^{26}$ Leyendas amazónicas de Elías Lozada Benavente y Sachachorro de César Lequerica de 1942. Estas obras del tetracentenario fueron publicadas por las razones circunstanciales que evoqué previamente y si bien acercan mitos y leyendas amazónicos a los lectores peruanos, representan un paréntesis en la larga historia de olvido de la selva. Añado a esta lista dos obras del escritor loretano Juan Coriat: Tunchi. Leyendas loretanas y Un amargado. Novela, criti$c a$, leyendas, ambas publicadas en 1944 por cuenta propia ${ }^{27}$ y cuya circulación parece haber sido bastante limitada. Los ejemplos citados son obras en las que la autoría es reivindicada y la fuente tradicional de las leyendas están disimuladas cuando no calladas, además son libros volcados enteramente hacia lo amazónico y, en particular, a lo loretano como lo indican varios de los títulos. A diferencia de estas publicaciones, Mitos, leyendas y cuentos peruanos incluyen relatos de la Amazonía en una recopilación que es pensada como representativa de todo el Perú, como "expresión integral" del país, según cita Izquierdo Ríos. Como lo indica la contraportada explicativa de la colección que publicó esta obra, "fiel a sus objetivos, entre los que ocupa lugar preferente el de contribuir a la afirmación de una auténtica conciencia nacional, la COLECCIÓN ESCOLAR PERUANA tiende a formar bibliotecas en las escuelas y colegios de la República, aportando un fondo de obras selectas de autores peruanos o referentes al Perú” (Arguedas e Izquierdo Ríos, 1947). Así, el valor peruanista de la obra es lo que más se recalca en esta edición y la inclusión de relatos de la selva marcó un precedente. Este

26 La primera edición de esta obra es de 1938, pero se publicó en Argentina por la Editorial Tor.

27 Es lo que indica Coriat en su prólogo a Tunchi y lo que parece indicar el nombre de la editorial "Librería Coriat". 
hecho fue motivo de orgullo para Francisco Izquierdo Ríos, no solo porque alentó un folklore peruano integral con el aporte amazónico, sino también porque la recopilación por los maestros y alumnos de todo el país "adquirió contornos de profundo movimiento nacional” (1975, p. 311).

\section{Conclusión}

Este caso de estudio sobre la formación de un intelectual amazónico y el paso del proyecto de la revista Trocha en Iquitos al de Mitos, leyendas y cuentos peruanos en Lima revelan cómo en la década de los cuarenta, en la que se estaba formando un folklore nacional, Francisco Izquierdo Ríos contribuyó a incluir sistemáticamente lo selvático a lo peruano desde su autoproclamado rol de difusor de la cultura amazónica. Muestra también el cambio a nivel nacional del saber vernáculo y de las tradiciones populares como un elemento que tiene su lugar en la escuela, un hecho seguramente influenciado por la Ley Orgánica de Educación Pública de 1941. ${ }^{28}$ Si bien Izquierdo Ríos contaba en Iquitos con una red intelectual local formada por maestros, periodistas, artistas y médicos, una vez en Lima se apoyó en sus antiguos contactos magisteriales y en las instituciones para llevar a cabo su labor de recolección de tradiciones amazónicas. Al ser uno de los escasos gestores de la institucionalización del folklore

28 Dentro de las misiones de la Dirección de Educación Artística y Extensión Cultural del Ministerio de Educación Pública, la nueva ley prevé "Impulsar los estudios folklóricos y velar por la conservación del folklore nacional" y abre una "Sección Editorial y de Bibliotecas Nacionales Populares". Por otra parte, el artículo 101 orienta la enseñanza "dando preferencia a las peculiaridades de la región". 
amazónico, esta acaba por limitarse a la visión de un solo hombre que conoce fundamentalmente la tradición mestiza de algunas ciudades y pueblos de la Amazonía, pero que no deja de ser la introducción de una cultura marginalizada en la esfera de la cultura nacional. Estas páginas sobre Francisco Izquierdo Ríos son solo un esbozo del quehacer intelectual del escritor. Otras de sus facetas, como su contribución a la literatura para niños y al género de la llamada "novela de la selva", son necesarias para tener una mirada cabal de su papel como introductor del elemento amazónico en el corpus literario peruano. 



\section{Javier Dávila Durand: poeta, periodista y editor}

\section{Javier Dávila Durand: poet, journalist and editor}

Kristel Best Urday ${ }^{1}$

Universidad Andina Simón Bolívar (Ecuador)

\section{Jornadas del Libro Loretano y la nueva poesía ama- zónica}

En 1956, surgió en Lima la iniciativa del Festival del Libro y la institución Patronato del Libro Peruano impulsadas por el escritor Manuel Scorza con el respaldo de intelectuales como Sebastián Salazar Bondy, entre otros. El festival tuvo cuatro ediciones hasta 1958 y se replicó en diversos lugares del país y del continente (Gras, 2009). En la década de 1960, Scorza fundó la editorial Populibros. Ambos proyectos se trazaron el objetivo de generar el acceso a la lectura de manera plural con libros de bajo costo y de gran calidad literaria dirigidos a la ciudadanía en general.

De manera simultánea e independiente de estas iniciativas, pero compartiendo la motivación y contextos, se lanzó en Iquitos la Primera Jornada del Libro Loretano en 1957, di-

1 Ha desarrollado la investigación y curaduría de la exposición La casa sin puerta. Literatura amazónica (1940-1980).

Contacto: kristel.besturday@gmail.com 
rigida por Víctor Raúl Hidalgo Morey, Luis Hernán Ramírez e Isaías Gómez Linares, con el diseño gráfico del artista plástico Víctor Morey. ${ }^{2}$ Esta primera edición estuvo conformada por los poemarios La ermita de mis ensoñaciones de Luis Chávez, Pan y fronda de V. R. Hidalgo, Poemas de soledad y sombra de Luis Hernán Ramírez, Mis delirios de Javier Dávila Durand y La búsqueda del alba de Germán Lequerica. Este último marcó un hito en la poesía amazónica por su estilo intimista y, al mismo tiempo, social (Molina Campodónico, 2011). Fue considerado, décadas después, un referente para César Calvo Soriano. Por otro lado, en Delirios, primer poemario de Javier Dávila Durand, se perfila un estilo que va desde el corte romántico amoroso hasta el corte simbólico. Su visión distinta de la Amazonía, como se dice en el prólogo, se inscribe en una poética de corte universal que deja de lado los regionalismos:

Viajero incansable, sus andanzas le llevan a cerrar el circuito dimensional en rápidas estadas en Lima, de donde ha ido asimilando las esencias que, al fundirse con sus vivencias de floresta, originan la nueva fisionomía de las letras loretanas, con integración definitiva a lo nacional. [...] abarca a la selva, ya no en sus limitaciones folklóricas o estrictamente "regionalistas», como mundo aparte del mundo -sino en su realidad espacial y de promesa universal. [...] Pero está también el «mundo aparte», que se mete por los poros y por la conciencia y grita -a veces- su grito de soledad (1957).

Transita de versos como La selva es el jardin de Dios a versos con una mirada menos esencialista y más compleja de la

2 Víctor Morey (1900-1965) fue autor del libro de cuentos El motelo, publicado por Juan Mejía Baca en 1958 con prólogo de Ciro Alegría. En 1962, fundó la Escuela de Bellas Artes de Iquitos que lleva su nombre. 
Amazonía como En todos los caminos se quebrará el paisaje o Selva. Albor. Orquestón en las aves o Selva. Alborea. Mesa, platos y cuchara. En estos últimos, se revela su búsqueda por una mirada propia, en la cual la relación entre la naturaleza y las personas es compleja, y no gira solo en torno a la contemplación o exaltación (sea paraíso o infierno verde), ${ }^{3}$ sino que plantea habitar en lo cotidiano, con los sentidos y en el presente.

En 1952, la publicación del poemario Selva lírica, que reúne a Germán Lequerica, V. R. Hidalgo Morey y a D. Linares, y la Jornada del Libro Loretano en 1957 dieron inicio a la poesía amazónica del siglo XX y a una serie de inventivas editoriales que tenían en común valorar y difundir la literatura amazónica.

Posteriormente, en la década de 1960, aparecieron dos iniciativas: el Primer Festival del Libro Amazónico, codirigida por Isaías Gómez, y Ediciones Populares Selva, ambas impulsadas por el poeta, narrador y periodista Róger Rumrrill. En el Primer Festival del Libro Loretano se publicó la antología Narradores de la selva (1966) con la selección, prólogo y notas de Rumrrill.

\section{Yara y la dimensión mágico mítica}

En 1966, en Ediciones Populares Selva, dirigido por Róger Rumrrill, apareció el segundo poemario de Dávila titulado Yara. El libro cuenta con tres secciones: la primera sección carece de título, la segunda se denomina "El cantar" y la

3 Giuliana Vidarte (2016) analiza los tópicos "paraíso del diablo" en la obra del fotógrafo Antonio Wong Rengifo. 
tercera, "El mito". En la primera sección, se desarrolla una autodefinición del yo poético con relación al amor de pareja y su vínculo con la naturaleza. Aparecen elementos de la naturaleza como el viento, la luz, las alas, la luna y el río, y personajes como el pescador, que simboliza la relación entre el ser humano y la naturaleza. El yo poético se define como un río, en el que tiempo y territorio se conjugan:

\section{YO PUDE SER UN RÍO}

Yo pude ser un río.

Fluvial

mi espíritu

por todas las orillas.

Viajero mis pies

de agua

retratando al mundo.

Ser un río

al fin

y sobre todo

un río donde el niño

alienta

su barco de papel

y el hombre

encuentra el puerto

de los vientos alisios

Un río.

Yo pude ser un río... (1957) 
En la sección "El cantar", desarrolla una poética a partir del amor de pareja con un tono e imágenes candorosas, que no están directamente vinculadas con temas amazónicos. En la última sección, "El mito", desarrolla de manera poética el mito de origen asháninka de Yara y Naro-wé. Yara es una "princesa" de la selva que proviene de los ríos: "Yara a los cuatro vientos / de la vida, / hecha de yerba buena / y a la fiesta / del beso desarmado" (1966, p. 34). Naro-wé es un guerrero "Mi vida es una piragua. Mañana debo partir. / Extendiendo su mirada surca el río Naro-wé. / Coge las manos amadas y le enreda entre sus dedos. / Las manos de Naro-wé parecen remos" (1966, p. 37). Ambos están enamorados. Boriré es un brujo jefe que desea matar a Yara: "Boriré mira la noche con ojos / de brujo jefe. / Dardos de fuego en / las sombras los ojos de Boriré" (1966, p. 35). Esta sección tiene reminiscencias de la tragedia griega, en tanto cada personaje tiene un canto y existe un coro. A partir de este poemario podemos ver cómo la visión mítico-mágica de los pueblos amazónicos se incorpora en la literatura amazónica de la segunda mitad del siglo XX. Esta búsqueda poética será compartida por la generación de Dávila Durand tanto a nivel literario como cultural y político y su obra encontrará mayor expresión con la novela Las tres mitades de Ino Moxo y otros brujos de la Amazonía de César Calvo Soriano.

\section{Trayectoria a partir del grupo Bubinzana a la revis- ta Proceso: confluencias entre la literatura y el pe- riodismo}

En 1960, surge el grupo Bubinzana. En el número 4 de la revista Proceso se hace referencia a su fundación: «Lejos de todo formalismo burocrático, oficialesco, «Bubinzana» nació más como coincidencia y afinidad generacional. Germán Le- 
querica, Róger Rumrrill, Javier Dávila Durand, Teddy Bendayán, Jaime Vásquez Izquierdo y Manuel Túnjar fueron sus fundadores» (1966, p. 19). Sin embargo, en compilaciones posteriores ya no se considera a Germán Lequerica como fundador ni como miembro del grupo. También participaron Humberto Morey y los artistas plásticos Ángel Chávez, Augusto Riva y Yando Ríos. El grupo tomó su nombre inspirado en la novela Bubinzana. La canción mágica de la selva (1960) de Arturo Hernández, donde explora la visión mágica y chamánica, y fue la última de una trilogía compuesta por las novelas Sangama (1942) y Selva trágica (1956). Además, la bubinzana es una planta que crece en las riberas de los ríos y también es el nombre del canto del ritual del ayahuasca, también conocido como ícaro.

Esta generación nació en las postrimerías de la explotación cauchera (1870-1940), por lo tanto, creció bajo la sombra de la añoranza de un pasado cosmopolita y de bonanza. A través de las fotografías y algunos artículos de la revista Proceso, encontramos que Javier Dávila Durand y su generación reconocen como maestros a los historiadores Fernando Barcia y Alfonso Navarro Cáuper ${ }^{4}$ y al pintor César Calvo de Araújo, ${ }^{5}$ padre del escritor César Calvo Soriano. Desde una mirada contemporánea y urbana, el grupo buscaba romper con la tradición poética y narrativa anclada en la descrip-

4 Destacados intelectuales de generaciones distintas han dedicado su vida a investigar y destacar la importancia de Loreto en el proceso histórico nacional. En el número 2 de la revista Proceso se releva la labor de $\mathrm{Na}-$ varro Cáuper en el artículo «Revolucionario y cauchero, dos pasiones han incendiado su vida: el periodismo y la historia».

5 César Calvo de Araújo (1910-1970), escritor y pintor amazónico, autor de la novela Paiche (1963). 
ción paisajística. El grupo encontró sus motivos y forjó su compromiso cultural y político en el reconocimiento de los pueblos indígenas y sus cosmovisiones, tal como indica Róger Rumrrill:
"Nosotros, particularmente en lo que nos concierne, asumi- mos este mundo mágico desde adentro, lo vivimos peren- toriamente", declaraba hace poco Gabriel García Márquez, el autor de Cien años de Soledad que, como pocas obras literarias latinoamericanas, explora ya y devela la bullente raíz mágica de nuestra cultura. Los bubinzanos también asumimos esta realidad perentoriamente. Nos hundimos en nuestras raíces. [...] Vivir perentoriamente el mundo mágico latinoamericano desde adentro, con su barbarie, su violencia, su vitalidad. Develar este mundo, beber de sus raíces; $y$ asumirlo en sus valores fundamentales es oponer al unidimensionalismo de la sociedad burguesa, las categorías de la sensibilidad de lo mágico (1973, p.68).

Las revistas fueron proyectos colectivos y a través de estas dieron a conocer su poética, su postura política y entablaron un diálogo con su medio cultural. Publicaron las revistas Bubinzana (1965), Surcos (1969) y Trinchera (1969), esta última con corresponsales en Iquitos, Pucallpa, Yurimaguas, Tarapoto, Huánuco, Chiclayo, Arequipa, Argentina, Uruguay, Europa y Estados Unidos. De este modo, trazaron redes entre diversos medios culturales de otras provincias y de la capital. Asimismo, acorde con su época, a nivel político estaban inmersos en el ideal revolucionario de izquierda que luchaba por la justicia social; y a nivel cultural sostenían el ímpetu de transformar su realidad desde el plano simbólico, a partir del arte, la literatura y el periodismo.

El 28 de marzo de 1966 apareció la revista Proceso. Revista de la Amazonía para todo el Perú, un proyecto concebido y diri- 
gido por Javier Dávila Durand. En la columna editorial del primer número indica sus motivaciones y propósitos:

Esta nueva revista que hoy inicia su vida, viene a llenar un claro en el panorama periodístico de la Amazonía Peruana. [...] A nosotros, sin embargo, nos anima una indesmayable decisión de triunfar y dar para la selva la voz que oriente, esclarezca y divulgue. Esto es tanto más necesario cuanto que en la región amazónica se han abierto prometedoras vías de progreso y al mismo tiempo se han agudizado algunos problemas. [...] En general, «Proceso» será un proceso para la Amazonía y en general, también, un proceso para todo el Perú. Porque tanto esta región como este país necesitan un enjuiciamiento (1966, p. 1).

De este modo, la revista se inscribió como un proyecto periodístico para contribuir a la incorporación de la Amazonía en el proyecto de modernización del país impulsado por el primer gobierno de Fernando Belaúnde Terry (1963-1968) y el gobierno militar de Juan Velasco Alvarado (1968-1975). El primero planteó la colonización de la Amazonía ("la conquista del Perú por los peruanos" ${ }^{6}$ ), el trazado de carreteras y la industrialización a través de la explotación maderera, petrolera y la ganadería, pero negó la presencia, necesidades y derechos de los pueblos indígenas. El segundo promovió la reforma agraria en la Amazonía, que la revista Proceso apoyó

6 Un ejemplo claro es el episodio de la expedición del Requena al Yaquerana para unir los ríos Ucayali y Yavarí. Al respecto, en Proceso citan a Belaúnde: «No han terminado los días heroicos del Perú; y este es un episodio más de la conquista del Perú por los peruanos, porque esos valientes expedicionarios no han ido a buscar tierra para sí, sino para la nación». Se refiere a la expedición que los madereros realizaron sobre el territorio matsés (antiguamente conocidos como Mayorunas). En 1964, tras la oposición del pueblo matsés, que terminó en la muerte de dos madereros, el gobierno de Belaunde mandó bombardear la zona. 
plenamente. En ese contexto, la revista se planteó como una tribuna de debate ("enjuiciamiento") y de propuesta frente a los problemas de la Amazonía, mantuvo una mirada desarrollista, pero que toma en cuenta a los pueblos indígenas como actores sociales.

En "Los años son maravillosos", Dávila Durand rememora sus inicios en el periodismo y la génesis de Proceso:

Edito "Manguaré" con Oscar Imaña Ríos, un diario virulento y sacarroncha que me convierte en apestado de los caciques políticos de Pucallpa. Se empeora mi situación y voy a parar varias veces a la cárcel sin que por eso logren amedrentarme. «Manguaré» es adquirido como pan caliente. Me amenazan, me persiguen, me intentan liquidar. «Manguaré» derrota a los Atilas del pueblo, pero logran finalmente que el diario desaparezca. [...] De tales canteras emergió «Proceso» (1976, p. 55).

Esta tuvo como sede principal la ciudad Iquitos y también contó con sedes en Pucallpa y Lima, por lo que su circulación no solo fue a nivel regional, sino que aspiró a circular en el medio capitalino. La revista buscó ser un proyecto editorial moderno que incorporó paulatinamente diversos elementos: tenía publicidad, por lo cual fue posible su impresión y distribución; a partir del segundo número se incorporaron corresponsales de otras ciudades de la Amazonía; desde el cuarto número apareció la fotografía como un lenguaje primordial de la revista, ${ }^{7}$ también se añadió la sección de Perfiles de sociedad y en la portada aparecía la imagen de una modelo mujer, acorde con un discurso letrado y mediático, que en la actualidad se

7 Se publicó, por ejemplo, un ensayo fotográfico dedicado a la obra de Antonio Wong Rengifo. 
inscribe como un discurso patriarcal, pero que era considerado un signo de modernidad y liberación cultural.

Los temas que abordó fueron la política, la economía y todo aquello que giraba en torno a la problemática del petróleo y las polémicas sobre su nacionalización, el desarrollo ganadero, el debate universitario y la cultura, por lo que difundió la producción editorial y literaria amazónica (p. ej., el Segundo Festival del Libro Amazónico, la poesía joven loretana, entre otros).

La planta permanente de Proceso estaba conformada por el redactor Juan Saavedra y el fotógrafo Augusto Falconi. Sus más importantes colaboradores fueron el poeta y narrador Róger Rumrrill, el poeta pucallpino Jorge Nájar y el escritor César Calvo Soriano. Este último fue director del Instituto Nacional de Cultura de Loreto, redactor de la revista Proceso y participó en la organización de diferentes eventos culturales (como FICA). Su presencia en la Amazonía fortaleció y dinamizó el movimiento cultural urbano. Participó en la revista Proceso durante la década de 1970, periodo en que la revista se tornó la tribuna de apoyo al autodenominado Gobierno Revolucionario de la Fuerzas Armadas. En el décimo aniversario de Proceso, siendo César Calvo el codirector, publicó un homenaje a

220 Dávila en donde dejó constancia de los ideales políticos que compartían:

Pese a la negativa de Javier Dávila Durand, y apelando no sólo a mi condición de co-director de "Proceso" [...] es que impongo en este número el artículo que sigue: una crónica que escribe desde siempre. Más que una crónica, es una verdad del corazón. Y más todavía, es un homenaje. Mi homenaje al poeta, al periodista, al hermano Javier Dávila 
Durand. El homenaje de mis recuerdos futuros a ese muchacho lejano y esmirriado que allá por mil novecientos cincuentaytántos, desterrado en un cuarto de la Pensión «Belén» en Lima, me obsequió los secretos de la poesía y del canto. [...] Respaldamos el proceso de transformaciones estructurales que realiza la Fuerza Armada» escribió Javier Dávila Durand en la Nota Editorial de «Proceso» del mes de julio de 1972. Y esa sigue siendo nuestra posición (1976).

\section{Las tres mitades de Ino Moxo: de periodista a perso- naje literario}

En 1981 apareció la novela Las tres mitades de Ino Moxo y otros brujos de la Amazonía de César Calvo Soriano publicada por Proceso editores, con los grabados del artista suizo Francisco Mariotti y las fotografías de Augusto Falconi e Iván Calvo. Esta obra cumbre de la literatura peruana se nutre del contexto cultural amazónico en el que ahonda el autor para su proceso de escritura. Calvo Soriano viajó, entre otros lugares, a la ciudad de Iquitos para la preparación de su libro, donde conoció a Javier Dávila Durand, quien era discípulo de su padre, el pintor César Calvo de Araujo. A través de Dávila Durand, Calvo Soriano se encontró con las cosmovisiones de los pueblos amazónicos. Esta novela relata la búsqueda y encuentro con el chamán mestizo Ino Moxo (Manuel Córdova Ríos), quien condujo al protagonista al universo de las plantas sagradas como la ayahuasca. Este le enseñó y presentó sus secretos y rescató del olvido el saber del pueblo amahuaca y lo confronta con otros saberes dominantes. A través de las visiones que tiene el protagonista, se hace un recorrido por la historia de la Amazonía y del país, en los que se denuncia periodos invisibilizados como la explotación del caucho que esclavizó y aniquiló a los pueblos amazónicos. 
Algunos antecedentes sobre Manuel Córdova son la entrevista y reportaje "Este hombre derrotó al cáncer" de Róger Rumrrill, publicado en la revista Trinchera del grupo Bubinzana, y la publicación del libro Wizard of the Upper Amazon de Bruce Lamb, publicado en 1971. Una característica de la novela es que desafía el fino límite entre realidad y ficción, cuestionando el género de la novela. Calvo torna personajes a distintas personas que fueron fundamentales en su búsqueda creativa, entre ellos a Dávila Durand que aparece como Don Javier:

Al confiarme esta historia, mi primo César Calvo, nacido en esos lares, me volvió parte de ella, no sólo inauguró mi curiosidad y acrecentó la suya sino que fuimos presa de una misma obsesión: lograr lo que nadie había alcanzado en más de dos décadas: entrevistar a Ino Moxo, legendario jefe de los amawaka. Con César viajé de Lima a Pucallpa, de Pucallpa a Atalaya, de Atalaya al capricho del clima y de los ríos, a lomo de piragua, hasta ese territorio agazapado tras el río Mishaw. En el trayecto conocimos a otros brujos, Don Javier, Don Juan Tuesta, Don Hildebrando, Juan González, y recopilamos otras historias, hechos y personajes que fueron desbordando las intenciones de nuestro reportaje (1981, p. 21).

En esta novela, se propone la búsqueda de las distintas concepciones de mundo, de tal modo que se logra una síntesis en la que la dimensión mágico-mítica o la visión

222 chamánica atraviesa todas las otras dimensiones de la vida social, política, económica. De este modo, la visión mítica nos permite explicar la historia. Por otro lado, la inclusión del personaje de don Javier y de otros agentes culturales de la Amazonía, como los pintores César Calvo de Araujo o Yando Ríos, enmarca al personaje real Javier Dávila Durand dentro de un proceso creativo colectivo como un destacado conocedor de la Amazonía. 


\section{Conclusión}

A través de la trayectoria literaria y periodística de Javier Dávila Durand nos podemos aproximar a la dinámica cultural de Iquitos y Pucallpa desde fines de 1950 hasta la década de 1970. Encontramos que su labor generó nexos entre los ambientes intelectuales, artísticos y periodísticos de las distintas ciudades de la Amazonía y pugnó para estos sean visibilizados y tengan un diálogo equitativo con la capital. Sus inicios se inscriben en un ideal político revolucionario que en el plano artístico estaba vinculado con la búsqueda poética en las cosmovisiones de los pueblos amazónicos. Dávila Durand persiste y deriva en una labor periodística crítica y, al mismo tiempo, lleva a cabo una labor militante que apuesta por la modernización de la Amazonía. En el plano literario y cultural, Dávila Durand y su generación dialogan con el pasado cauchero, son interpelados por ese pasado reciente y consiguen elaborar una mirada crítica sobre él.

Cabe resaltar que esta investigación preliminar ha sido posible por la consulta a los archivos personales del escritor. Por ello, consideramos de vital importancia preservar y estudiar los archivos de los escritores contemporáneos para construir una historia de la cultura letrada en la Amazonía, que se ha construido en permanente relación con las cosmovisiones de los pueblos amazónicos. 



\title{
Arnaldo Panaifo Teixeira, el surgimiento de un narrador amazónico y de nuevas vías editoriales
}

\author{
Arnaldo Panaifo Teixeira, the emergence of an \\ Amazonian narrator and new ways of publishing
}

Yaneth Sucasaca ${ }^{1}$

Casa de la Literatura Peruana

\section{Arnaldo Panaifo y su lugar en la escena literaria ama- zónica y nacional}

A finales de la década de 1970 y principios de 1980, la Amazonía experimentó grandes cambios por la explotación petrolera y maderera, y la construcción de carreteras durante las décadas anteriores que modificaron el bosque amazónico, lo que sumado a la irrupción del narcotráfico y la presencia de Sendero Luminoso y el Movimiento Revolucionario Túpac Amaru generó que las poblaciones indígenas migraran a la ciudad, acelerando el proceso de transformación espacial de la Amazonía, que conllevó a la repentina explosión de la marginalidad urbana. Al mismo tiempo, se complejizaron las dinámicas culturales de la región, la UNAP, ya con

1 Investigadora de la Casa de la Literatura Peruana. Ha desarrollado la investigación y curaduría de la exposición La casa sin puerta. Literatura amazónica (1940-1980).

Contacto: yanethsucasaca@gmail.com 
algunos años de creación, había formado a varias generaciones que configuraron un nuevo tipo de intelectual que asumió su compromiso con la historia y ecología con mayor intensidad, y que fue parte de luchas concretas que reivindicaron la identidad amazónica a partir del vínculo con el territorio y la posición anticentralista; una muestra de ello es que la mayoría de los intelectuales de ese periodo buscaron quedarse y desarrollar su vida intelectual en su lugar de origen.

En Iquitos aparecieron interesantes grupos y asociaciones que dinamizaron el ambiente cultural. En 1979, de las aulas de la UNAP surgió el Grupo Cultural Urcututu convocado por Manuel Luna e integrado por los poetas Carlos Reyes, Ana Varela, Percy Vílchez y Humberto Saavedra. En la revista Carachama, donde publican sus primeros poemas, apelan al archivo histórico y denuncian la devastación de la naturaleza lo que "les permite formular su propia versión de la historia literaria” (Molina Campodónico, 2015, p. 5). En ese mismo periodo apareció el Grupo Oruga de Acción Cultural, que tomó el nombre del cuento La oruga que quería vivir del narrador y educador Orlando Casanova. Estuvo integrado por Germán Lequerica, Virginia Roca, Nancy Dantas, Luis Hernán Ramírez, Carlos Fuller, Alejandro Eléspuru, Fernando Santos, Frederica Barclay, Edwin Rojas, Jarle Mel-

226 lemstrand, Lando y Zoltán Keserü, entre otros. De manera simultánea, inició sus actividades el Grupo Literario Javier Heraud, el Grupo Nueva Cultura y el Grupo Cultural Jovaldo. Asimismo, surgieron voces particulares, como los narradores Arnaldo Panaifo, Miguel Donayre y la poeta Sui Yun, quienes no se adscribieron de manera permanente a ningún grupo. La efervescencia cultural de ese periodo proyectó voces nuevas en la literatura amazónica, que construyeron 
una poética propia y -desde distintas trincheras- asumieron parte de un mundo mítico y urbano a la vez.

En ese contexto creativo, el narrador, poeta, periodista, editor, locutor y perito forestal Arnaldo Panaifo Teixeira (19482005) es un caso significativo. A continuación, trazaré la trayectoria del escritor, editor, gestor cultural y periodista con el fin de presentar su obra y entender sus estrategias editoriales y prácticas personales para configurarse como un intelectual que dialoga con autonomía y busca generar una episteme alternativa "capaz de incluir términos no lineales, opuestos, zonas de conflicto y encuentro, nuevos puntos de partida” (Rivera, 2015, p. 7).

Arnaldo Panaifo irrumpió en la escena literaria iquiteña en 1974, cuando ganó el segundo premio en el concurso de cuentos navideños organizado por el CETA, ${ }^{2}$ con su relato La navidad de José Manuel. Al año siguiente, obtuvo una mención honrosa en los Juegos Florales de la Universidad Nacional de Piura con su relato Shapiama el curandero. En 1978, ganó el Premio Alfonsina Storni de Poesía, convocado por la Fundación Givré de Buenos Aires por su poemario Esta noche la eternidad (1994).

Durante la década de 1980 y con el reconocimiento intelectual que le otorgaron los premios literarios, se publicaron sus libros más importantes: Cuentos y algo más (1981), El pescador de sueños (1982), El ocaso de Ulderico el multiforme (1986), Julia Zumba, la nodriza reina (1986) ganadora del segundo puesto en el Premio COPÉ de cuentos en 1985 y

2 Desde 1971, el CETA organiza una serie de actividades durante las fechas navideńas con el fin de "recuperar la identidad amazónica". 
El parpadeo insomne (1987), premiado en los Juegos Florales Bodas de Plata de la Universidad Nacional de la Amazonía Peruana (UNAP, 1987). Además, entre 1988 y 1989 publicó varios de sus poemas en su columna del diario El Matutino de Iquitos con el seudónimo Aldo Patei. En las décadas siguientes, su obra se consolidó con la publicación de los libros de cuentos Piñón a babor (1991), Los jóvenes de la serial (1992), Mericha (1993), Un tal Saturnino Olavarría (1994), Cuando florecen los mangos (2000), La chacra de los pies desiguales (2003); las narraciones infantiles Shamiro (1991), Rio encantado (1992), La Lamparilla (1994), Los conta (1997), El planeta de los conceptos (2001), Cerro Azul (2003); las novelas Cushuri (1998), Los decires de Fasanando (2000); y los poemarios Esta noche la eternidad (1994) y Palabras para el shamán (2006).

La mayoría de estos libros fueron publicados en Iquitos por Shamiro Editores, ${ }^{3}$ sello independiente que él mismo fundó ante las complicaciones que conlleva publicar un libro en una región como Iquitos. $\mathrm{Al}$ respecto, en la crónica Arnaldo. El narrador, Panaifo afirma:

Lo hice $[. .$.$] porque no me gusta estar supeditado a los ca-$ prichos de los editores y pensando, además, si el público me brinda su preferencia, fundar mi propia editorial para apoyar a los nuevos valores que surjan en nuestra Amazonía y publicar sus creaciones, y evitarles, de esta manera, todas las peripecias y angustias por las que yo he pasado. Quiero que esto sea mi mayor aporte a la cultura de nuestro pueblo (Perspectiva. s/f.).

3 Aunque Panaifo afirma haber creado la editorial para difundir su obra y la de sus contemporáneos, aún no hemos ubicado títulos de otros autores publicados por esta editorial. 
De esta manera, tomó conciencia de la importancia de la praxis editorial en el circuito intelectual moderno para aglutinar la creciente actividad cultural y decidió hacer suya esta práctica y con esto se configuró como un actor de la dinámica editorial de su región. Sin embargo, esto no hizo que prescinda de sus vínculos con otros actores editoriales, pues también publicó con Ironyodla Editores de la escritora de literatura infantil Nori Rojas y con Lluvia Editores, sello de Esteban Quiroz, que en la misma década incentivó la lectura de maneras poco convencionales y animó y publicó a jóvenes escritores que no tenían cabida en otras editoriales. Con esta última editorial participó en la Serie Amazónica donde aparecieron El parpadeo insomne, Julia Zumba, la nodriza reina y Piñón a babor.

Sus publicaciones inicialmente generaron respuestas a nivel regional, se publicaron reseñas, comentarios en medios locales y se organizaron eventos para presentar sus publicaciones. Por ejemplo, el escritor Humberto Morey, la gestora cultural Marina Díaz y el locutor y periodista Tito Rodríguez Linares comentaron y presentaron en el Consejo Provincial de Maynas (Iquitos), el libro Cuentos y algo más, prologado por el escritor huaracino Marcos Yauri Montero. Asimismo, se publicaron notas en el periódico El Matutino de Iquitos. Estas acciones motivaron la valoración de su obra por escritores de otras regiones y ayudaron a consolidar vínculos con actores culturales de otras regiones. También Julia Zumba, la nodriza reina y El parpadeo insomne fueron comentados en diarios, como El Oriente de Iquitos, Selva de Pucallpa y La Crónica de Lima, entre otros. En 1989, Alejandro Eléspuru publicó una reseña en el diario El Matutino de Iquitos sobre el libro El ocaso de Ulderico el multiforme, prologado por el poeta iquiteño Germán Lequerica, la carátula elabo- 
rada por Jesús Ruiz Durand y reeditado por Roger Rumrrill como parte de la serie Municultura Amazonía Siglo XXI. Esta colección fue auspiciada por el gobierno municipal con el propósito de "ser una trocha", es decir, un hito en la incorporación de autores regionales en la agenda literaria nacional. Estas últimas publicaciones consolidaron el lugar de Panaifo en la escena literaria amazónica.

Este itinerario se completó a fines de la década de 1980 y principios de 1990, cuando la obra de Panaifo Teixeira amplió su horizonte de recepción. A pesar de las dificultades del intercambio editorial con Lima y otras regiones del país, su obra superó los límites locales. Diversos periódicos limeños reseñaron su obra, como La República y Opinión, en el que el escritor Maynor Freire comentó el libro Un tal Saturnino Olavarría y el poemario Esta noche la eternidad. Al mismo tiempo, su obra continuó consolidándose en la Amazonía, se publicaron comentarios en periódicos y revistas como $E l$ Matutino, El Oriente, El Diario de Iquitos, Kanatari y la revista Amazonía, en este último, el crítico Luis Hernán Ramírez hizo un análisis concienzudo de la producción de Panaifo. Asimismo, los medios La Semana y Carta Abierta de Pucallpa comentaron las actividades y publicaciones de Panaifo.

Durante esos años el autor acrecentó su actividad cultural.

230 En 1992 fue nombrado miembro de la mesa directiva del I Congreso Nacional de Literatura Infantil y Juvenil "César Vallejo" realizado en Huamanga, adonde se trasladó para participar en el evento y difundir sus publicaciones. En 1994, viajó a Lima y participó en el XIII Encuentro de Literatura Infantil y Juvenil realizado en la Universidad Nacional de Educación Enrique Guzmán y Valle - La Cantuta. Ese mismo ańo fue invitado a participar en Caraz en el V Encuentro 
de Escritores Peruanos Carlos Eduardo Zavaleta y ahí se vinculó con los escritores Cromwell Jara, Félix Huamán Cabrera y Oswaldo Reynoso, este último mostró gran interés por la producción literaria de Panaifo.

Estos vínculos le otorgaron prestigio intelectual a nivel local y nacional y afianzaron su lugar en las dinámicas culturales regionales. No obstante, la crítica académica tuvo poca atención a la obra de Panaifo con excepción de Luis Hernán Ramírez, cuyo artículo Arnaldo Panaifo Teixeira. El drama de la selva en sus relatos, publicado en la revista Amazonía, es quizá el análisis más minucioso de su obra. Por su lado, Manuel Marticorena tituló su libro De Shamiros Decidores. Proceso de la literatura amazónica peruana (de 1542 a 2009) (2009), a manera de homenaje a la revista editada por Panaifo, y lo ubica en un lugar importante en su periodización, específicamente en el ciclo del boom petrolero y del narcotráfico (1960-2009). Marticorena destaca el lirismo de su producción poética y lo real maravilloso de su narrativa. Asimismo, Armando Ayarza, en su periodización, ubica la obra de Panaifo en el periodo del petróleo y la coca, en la línea de los narradores de 1980-2000, junto con los escritores Juan Saavedra Andaluz, César Calvo Soriano, Ulises Reátegui, Orlando Casanova, Miguel Donayre, Jorge Luis Salazar, Igor Calvo y Vendrino Reátegui.

La obra de Panaifo ha sido incluida en diversas antologías. ${ }^{4}$ En 1991, el grupo Oruga de Acción Cultural y el COPAL publicaron Poesía y narrativa amazónica, una selección rea-

4 Este punto da cuenta de la relevancia de Panaifo en la tradición amazónica, pues una antología tiene como principal característica la selección de lo más representativo. 
lizada por Fernando Santos Granero y Frederica Barclay, donde incluyeron el cuento Mericha, el lunar insomne. En el número 300 de 1990, la revista Kanatari hizo una edición especial titulada Forjadores de la cultura. Antología de la literatura regional, en la que incluyeron el cuento "El pescador de sueños". Recientemente, el número 6 de la Revista Peruana de Literatura publicó la edición Loreto, un río de literatura. Su editorial destaca a Germán Lequerica, Orlando Casanova y a Arnaldo Panaifo y presenta una antología que incluye los poemas XXXII y XXXIII de Palabras para el shamán.

Por último, el mismo autor es consciente del lugar de su obra dentro de la tradición literaria. Al consultársele por su producción literaria, él afirma:

No me considero un escritor descriptivo, más bien un agitador de conciencias, porque trato de hacer comprender la realidad de quienes intervienen en mi obra. Considero que he encontrado mi propio estilo que se trasluce en los cuentos "Retazos de infancia" y "El tren Juan Inuma". Los críticos me manifestaron que he dado una evolución a lo que se ha escrito de Perú, porque no hago una simple descripción del paisaje sino pongo activo al hombre de la selva (El Matutino. Iquitos, 16 de marzo de 1982).

De este modo, el escritor se ubica en una larga tradición de narradores representativos de la Amazonía, que se inició con Jenaro Herrera y Humberto del Águila, quienes presentaron personajes y paisajes de la literatura oral. Estos tuvieron continuidad en la llamada generación del IV Centenario del Descubrimiento del Río Amazonas, que surgió en la década de 1940 conformada por Arturo Hernández, Francisco Izquierdo Ríos, César Lequerica, 
Arturo Burga Freitas y César Calvo de Araujo, entre otros, que dotan de gran importancia a la naturaleza y al personaje ribereńo de la Amazonía y que abrieron la trocha para el surgimiento de narradores posteriores como Roger Rumrrill, Jaime Vásquez Izquierdo y otros que buscaron presentar una Amazonía compleja con procesos particulares muchas veces desligado del resto de la nación peruana. En ese marco, sus vínculos, así como los reconocimientos que ha merecido su amplia actividad cultural, las ediciones y reediciones de su obra, le otorgan a Arnaldo Panaifo un lugar preponderante en la tradición literaria de la Amazonía y representan elementos para ampliar el estudio de su obra, de modo que aporte nuevas voces a la historiografía literaria.

\section{La narrativa de Panaifo y las visiones míticas de los pueblos amazónicos}

Panaifo ha explorado casi todas las formas literarias, siendo el cuento el privilegiado y en segundo lugar la novela y la poesía. Su obra presenta el paisaje amazónico y personajes ribereños en vínculo con la naturaleza. Aborda problemáticas habituales en un contexto de modernización acelerada, como la pobreza, el sueño, la inocencia, la esperanza, la violencia y la rebeldía, los cuales son explorados desde las visiones míticas de los pueblos amazónicos y conjugados con la defensa del medio natural y una fuerte crítica a la depredación de los recursos de la Amazonía. De sus más de veinte libros, por razones de espacio, destacaremos tres por considerarlos representativos de su narrativa.

En El pescador de sueños, presenta los cuentos El pescador de sueños, El último vuelo y El vaivén de las estaciones, todos 
enmarcados en el mundo amazónico. El primer cuento narra la historia de Julián, joven pescador que vive una experiencia mágica al ser trasladado al mundo subacuático, donde la vida se desarrolla de manera paralela al mundo terrestre:

[...] Este es el reyno de las aguas, un lugar que como tú ves es hermoso. El río corre sobre nuestras cabezas y podemos viajar por él a cualquier sitio. Julián escucha sorprendido. Levanta la cabeza y ve que las aguas corren sobre él. Pasea la vista y aprecia el lecho donde durmió y se embelesa con las escamas plateadas y multicolores (1982, pp. 28-29).

El cuento trae a la memoria el vínculo entre el poblador amazónico y la naturaleza, el río, los peces, el bosque; de estos, el río adquiere gran importancia, al ser el lugar donde habitan seres sagrados, el camino por el que Julián puede viajar a cualquier lugar y es también su principal fuente de trabajo. Así, el narrador le presenta al lector la relación misteriosa entre el ser humano y el medio que lo rodea, lo invita a cuestionarse sobre su historia y memoria, su vínculo con la naturaleza y el lugar que tiene respecto a ese territorio.

El último vuelo narra el devenir de Jacinto, un niño lustrabotas que vive en la calle y se enfrenta al abandono de la sociedad. Si bien es cierto que no se menciona un periodo específico, el narrador enmarca el relato en el mundo urbano de la Amazonía de las últimas décadas, en un ambiente donde el cemento ha cobrado preponderancia y las drogas son de uso común, sobre todo, entre los habitantes de la calle.

En El vaivén de las estaciones narra la historia de José Antonio, un niño que se moviliza diariamente a través de un río para ir a la escuela; muestra la fuerza de la naturaleza y la 
capacidad del río de dotar de vida como de quitarla, de modificar el rostro de la Amazonía misma:

Pero el río está creciendo y todo lo que en el verano fue propiedad de la tierra se está convirtiendo, a medida que las lluvias persisten, en propiedad de las aguas. Ahora al Ucayali le está creciendo el cuerpo, cada día que pasa se vuelve más apasionado (1982, pp. 64-65).

Otro libro importante es El ocaso de Ulderico el multiforme, en el que destaca el cuento que lleva el título del libro. El narrador presenta a Ulderico, un ser vinculado al tohé y a la ayahuasca, que transmuta por siglos en distintos seres de la naturaleza, como el lodo, peces, insectos, entre otros, hasta que en el tiempo presente logra renacer como hombre; sin embargo, este proceso irá de la mano con su transformación en un líquido negro que arrasa con ríos y bosques y que muchos ribereños quieren atrapar debido a su costo monetario. El relato es quizá uno de los más claros al retratar el drama de la Amazonía y presentar el transcurrir de siglos enteros de una Amazonía agónica, que se enfrenta a distintos cambios sociales, económicos y demográficos. Hace alusión a los ciclos extractivistas, las migraciones forzosas que estos acarrean y la perversión a la que conllevan estos procesos en sus habitantes, con esto último aparentemente da a entender que transformación es igual a destrucción. No obstante, esto se cuestiona al evidenciarse que se trata de un relato cíclico; sabemos que Ulderico continuará transformándose, que volverá a ser lodo, carachama, mariposa y otros seres que permitirán regular el medio:

Sin más herramientas que el Collin's en las manos se enrolaron en las compañías para volver a la selva en busca del cuerpo negro que surgió del río, de las entrañas de la tierra. Debían atacarlo, cercarlo, cazarlo, maniatarlo y exportarlo 
en barriles. Abrieron venas y destruyeron el bosque, la fauna, con la esperanza de volver a retozar la choza incrustada en la ciudad. Atrás quedaba el pasado campesino de la chacra y el chicosal (1986, p. 68).

El relato sin duda no está culminado, prueba de ello es que la historia dialoga con el poemario inédito ${ }^{5}$ El cantar de Ulderico, que ganó el primer Premio Alborada Amazónica, donde conocemos a Ulderico con su propia voz.

La protagonista de Julia Zumba, la nodriza reina proviene de una tribu jíbaro, cruza el río y llega a un internado en Intuto, donde conoce a Gumercindo Talexio, con quien vivirá una larga y agónica relación. En la narración se aborda el vínculo de Julia con su pasado y nos adentra en un mundo de rituales, costumbres y hechizos que conviven ahora en un universo urbano.

Y Julia Zumba bebió tanto oni xuma, madre y padre de las hierbas, que las cortezas y las plantas de la Selva anunciaron: "Julia Zumba, una purga más y te convertirás en la planta de la desilusión, en la planta de la desdicha, pero serás tan hermosa y tus frutos serán tan dulces y tus flores tan aromáticas que todo el que esté a kilómetros de distancia sentirá tu fragancia y vendrá a ti y al saborearte olvidará todo lo que tenía que hacer, adonde iba y vegetará hasta morir" (1993, p. 34).

Partiendo de estos relatos, se evidencia el vínculo entre proyecto estético e ideológico de Arnaldo Panaifo, sus narraciones rescatan la tradición oral y presentan un universo complejo donde se entreteje la vida ribereńa y el mundo mágico maravilloso conformado por seres reales, sirenas y otros se-

5 Revisado en el archivo particular del escritor. 
res mitológicos. Presenta de manera natural lo sobrenatural, mezclando las ficciones con la historia. En su universo narrativo, la "modernidad" y la tradición son parte del mismo entramado. Así, se apropia de elementos de la vida cotidiana y aborda los problemas sociales a los que se enfrentan las urbes amazónicas, su convivencia con la naturaleza, la depredación del medio ambiente y sus consecuencias. Encara los límites del español e inserta un vocabulario nuevo capaz de expresar la realidad amazónica. De este modo, los cuentos de Panaifo recrean un mundo en el que lo mágico y lo real conviven a través de sus personajes, quienes poseen una cosmovisión propia y son parte de una larga tradición cultural amazónica, que no es ajena al escritor, lo que le permite hiperbolizar algunos hechos y dotar de humor o de un cariz fantástico a sus cuentos.

\section{Los Shamiros Decidores: de la opinión política a la miscelánea literaria}

En noviembre de 1995 apareció en Iquitos el primer número de la revista de manufactura popular Los Shamiros Decidores, dirigido y concebido por Arnaldo Panaifo, que se extendió posiblemente hasta el $2003 .^{6}$ En la editorial del primer número se afirma que "La ciudad de Iquitos, Capital de la Región de Loreto, es una urbe cosmopolita que en las últimas décadas no tuvo un órgano de difusión en el que exprese sus sentimientos, aspiraciones, rebeldías y proyecciones al hombre de la Amazonía Peruana”. Así, la publicación nació con

6 He hallado 35 números de la revista entre 1995 y 2013; el último número hallado corresponde a febrero de ese ańo y tiene el número 85-86, lo que da una idea de la constancia de la revista. No sé con certeza si ese sea el último número. 
la urgencia de divulgar una escritura ignorada y constituir un corpus amplio y diverso.

El nombre de la revista es un homenaje a su libro Shamiro y se inspira en la denominación que reciben los loros en la Amazonía, sobre los que Panaifo afirma: "Son loritos que parecen estar siempre de carnaval, con sus ojeras amarillas como si fuesen lentes polarizados" (El Matutino, 1991). El contenido y el diseño fueron elaborados por él mismo con apoyo de su familia; su hija Nadia tipeaba los textos que Panaifo le dictaba y luego ella y su hermano acompañaban al escritor a distribuir la revista. ${ }^{7}$ Su formato es de bolsillo, fácilmente transportable de tamaño $\mathrm{A} 5$, las hojas son de calidad modesta y de distintos colores, la impresión es artesanal y no es prolija, la mayoría de los números de la revista tienen unas 20 páginas.

Esta publicación forma parte de un corpus inusual, a diferencia del común de las revistas. Para empezar, no tenía un consejo editorial permanente, los colaboradores no se involucraban en mayor medida y los únicos constantes eran Arnaldo Panaifo, como director, y Juan Santillán Pezo, ilustrador de la carátula. Este último gesto editorial posiblemente tenga que ver con una elección personal, que no es rara en revistas regionales, ${ }^{8}$ donde el editor abandona la colec-

238 tividad para optar por el emprendimiento individual con miras a representar a todo un pueblo. Por otro lado, para su distribución rompió con la dinámica editorial de una

7 Información brindada por Nadia Panaifo (2018).

8 Otro ejemplo importante de este tipo de revistas en la Amazonía es la revista No hay cultura sin lectura publicada en Lamas por el escritor y editor Carlos Maktangrunaka. 
revista. Los Shamiros Decidores, según me comentó su hija Nadia en el 2018, "se distribuía entre el público de a pie, el escritor acostumbraba hacer circular la revista en los espacios más transitados, la plaza, el mercado, la feria, buscaba tener un alcance real en la población iquiteña, se vendía a 1 sol y en algunos casos se regalaba”. También tenía como público predilecto a las escuelas, pues establecía vínculos con directores y profesores de los colegios iquiteños y ribereños, donde distribuía la revista. Desde el primer número, la publicación anunció su distribución a nivel nacional e internacional.

Como revista de carácter popular, aborda temas sociales, políticos y literarios, los que se desarrollan en sus distintas secciones. La estructura no siempre es la misma, sin embargo, hay secciones constantes y otras que se van ańadiendo según el contenido que se publica. La portada generalmente informa y comenta algunos hechos sociales y culturales. La editorial está destinada para reflexiones generales y en algunos casos para enunciar reclamos y denuncias. Otras secciones constantes son: Poesía, donde compila la obra de poetas extranjeros y locales; Concursos, que difunde la convocatoria de concursos literarios nacionales e internacionales; Opinión, en donde se comentan noticias políticas, sociales y culturales; y Publicaciones, que incluye reseñas de obras literarias de escritores de la Amazonía. Otras secciones que aparecen con alguna frecuencia en distintos números de esta publicación son: Música, Cuentos, Teatro, Literatura infantil, Voces populares, Crítica, Andariego Palacala, Los perpetuos decidores, Biografías, Premiados, Anécdota, Homenaje, Testimonios, Efemérides regionales, Pedagogía, Institución, etc. 
El ideario de Los Shamiros Decidores no se puede entender sin examinarlo de manera integral. La revista se publicó durante un periodo de grandes crisis sociales. Ante el incremento de atentados terroristas, se impuso el régimen dictatorial de $\mathrm{Al}$ berto Fujimori (1990-2000) y una política de corte neoliberal. Entre las diversas acciones, los medios de comunicación contrarios al régimen dejaron de tener visibilidad y los existentes compartían información sesgada.

Ante esta situación, Arnaldo Panaifo, quien también se formó como periodista, ejerció su oficio de manera poco tradicional, abandonó la opción de publicar en los medios periodísticos y optó por crear sus propios medios para un medio independiente, donde podía denunciar. De hecho, su experiencia más cercana al periodismo convencional fue su participación en una columna poética del diario iquiteño $E l$ Matutino y su trabajo en la radio como locutor, donde se encargó de informar y comentar noticias locales y nacionales. Sin embargo, a este último trabajo radial le añadió la función de relatar mitos, lo que sin duda reconfiguró la definición de periodista para que el trabajo vaya de la mano con lo literario.

De este modo, Los Shamiros Decidores nació de esta percepción propia de la práctica periodística. Panaifo reclamó al periodismo su falta de empatía con el poblador, su enclaustramiento y

240 en respuesta creó un medio acorde con su personalidad, uno donde la literatura y el periodismo se pudieran vincular con libertad. Así, la revista se erigió para extender el corpus editorial de Iquitos, denunciar el olvido y representar el sentir de este pueblo, se distanció del grupo oficial ligado al gobierno de turno y configuró su revista como un "[...] órgano de difusión cultural popular, en el que todo el pueblo puede y debe participar”. Esto incluso hará que se distancie del CETA, una de las 
instituciones de mayor trascendencia cultural en Iquitos. En la editorial del número 4 de la revista se afirma lo siguiente:

Frente a todo este panorama de desengaño y de estupidización colectiva que sufre la población, los visionarios Shamiros denuncian que todo el rosario de males: la extrema pobreza, el hambre, la desocupación, la inflación, la recesión, la prostitución, la entrega de territorio y de gente a las transnacionales extranjeras en la aparente venta de las empresas públicas [...], son acciones programadas que se cumplirán a las buenas o a las malas con la aprobación de los ayayeros mendigos del legislativo fujimorista y el poder de las armas de los mercenarios del ejecutivo.

Es hora de reflexionar y decidir si resignados morimos de hambre y de inanición o si salimos a las calles a protestar, pues creo que es mejor morir de pie y con dignidad (1996).

Además, pese a su publicación mensual, la revista cumplía la función de un periódico; en su editorial y en las secciones de opinión, el director mostró su interés por los problemas políticos y sociales, informó e interpeló a los órganos oficiales del país y de Iquitos, denunció la desidia de las autoridades y comentó el contexto político.

Tampoco abandonó la agenda ecológica, pues en varias secciones de opinión denunció la contaminación ambiental, la deforestación, la pesca indiscriminada y otras actividades que desequilibran el medio ambiente, como se puede ver en la editorial que publicó en el número 2:

[...] con esa fe en nuestros dioses y en nuestra cultura acuática, terca y bárbaramente interrumpida por la cultura europea es el reto que asumimos.

Aquí estamos y aquí seguiremos firmes como estos viejos árboles de cedro y caoba que a pesar de la brutal depredación, 
la madre naturaleza escoge los más intrincados parajes para seguir preservando la especie de pie, desafiantes y altivos con el orgullo de las etnias puras que rechazaron todo tipo de religión foránea, pues saben que ellas han contribuido a la castración de las razas y la indignidad lambiscona, arribista y desvergonzada de algunos peruanos (1995).

Esa es la agenda que mantuvo en sus obras literarias y que amplió en la revista, es decir, para realizar las denuncias se valió de los eventos reales acontecidos en la Amazonía y de las publicaciones de sus propios cuentos y de los cuentos y poemas que enviaron escritores que concordaban con la agenda de denuncia de la tala indiscriminada, los constantes derrames de petróleo, la pesca sin regularización, entre otros problemas perjudiciales al medio amazónico.

Por otro lado, la publicación le otorgó gran importancia al ámbito cultural y tuvo claro interés en rescatar algunas figuras consagradas y presentar a nuevos escritores, enmarcándolos en una tradición. Esto sin duda, le permitió generar nuevos vínculos con figuras como Armando Almeida Nacimiento, Remigio Reátegui, Carlos Fuller, Armando Ayarza, Nancy Dantas, Humberto Saavedra, Eleazar Huansi Pino, Humberto Zeballos, entre otros, quienes fueron publicados con cierta frecuencia en la revista. Del mismo modo, reforzó sus vínculos con actores culturales, con quienes compartía

242 ideales, así, tuvo constante comunicación con Enrique Solano de la revista para niños La Gota, con Raúl Zeballos de la revista Carta Abierta de Pucallpa, con José Guillermo Vargas de la Casa del Poeta en Lima, con Nancy Dantas y Marina Díaz, dos artistas y actoras culturales de Iquitos.

En sus más de 30 números, la principal alianza que entabló la publicación fue con los maestros y los estudiantes, ellos 
fueron los principales colaboradores y también el público destinatario, como queda claro en el número 10 de la revista:

Los Shamiros Decidores es un órgano de difusión de cultura popular de la Amazonía Peruana que promociona poetas, escritores, músicos, pintores, escultores y todo lo relacionado con el quehacer intelectual de los hombres de esta zona del país, permitiendo a los docentes y alumnos tener en sus manos mensualmente un material de consulta y texto de apoyo para las líneas de Lenguaje y Literatura a un costo relativamente simbólico. Poesías, cuentos, obras de teatro, crítica literaria, biografías, crónicas y publicaciones conforman la estructura de este medio que está logrando constituirse en un documento que reafirma la identidad de los loretanos (1997).

Las publicaciones de los maestros fueron recibidas y publicadas en casi todos los números, a esto habría que sumar la constante solidaridad que el director expresó hacia este gremio, el apoyo a las huelgas de profesores que se desarrollaron en esa década y los homenajes que realizó a profesores destacados. Además, el contenido de la revista fue presentado como material de trabajo para los profesores, lo que explica las secciones orientadas a un fin pedagógico, como las misceláneas literarias, que además de ser una herramienta de enseñanza, difundía la creación de escritores de la Amazonía, y buscaba constituir un corpus literario de escritores consagrados y noveles para la escuela. Al mismo tiempo, también fue un medio para instaurar la producción amazónica dentro de la tradición literaria nacional.

\section{Conclusión}

En un contexto complicado como el de las décadas de los ochenta y noventa, en los que fueron más patentes la 
inestabilidad económica, política y cultural en las regiones, Arnaldo Panaifo Teixeira asumió estrategias propias y se configuró como intelectual amazónico a partir de la apropiación de prácticas culturales que le permitieron insertarse en la tradición literaria amazónica como narrador, editor y animador cultural. La fundación de Shamiro Editores y la publicación de Los Shamiros Decidores revelan que Panaifo buscó crear y activar una red editorial amazónica que reafirmó su carácter independiente. Esto se contrasta con su vínculo con otras editoriales, donde también publicó sus libros, así como la relación que estableció con otras revistas de la Amazonía, lo que evidencia su búsqueda de insertarse en las redes editoriales de su contexto. Ambas prácticas dejan claro que Panaifo fue consciente de las practicas intelectuales que le permitirían ser parte del gran corpus literario. Es decir, Panaifo buscaba salir del lugar marginal que ocupaba en el campo intelectual ${ }^{9} \mathrm{y}$ asumió estrategias particulares para escapar del olvido, decidió ampliar el mapa cultural, diversificar el corpus de la historiografía nacional, configurar un nuevo tipo de periodismo y configurarse a sí mismo como un nuevo tipo de intelectual, distinto de la percepción del intelectual de élite o, en todo caso, del intelectual limeño. Parte de esa estrategia fue la creación de una editorial autogestionada y mantuvo el vínculo entre su praxis editorial y su búsqueda estética, conjugó el periodismo con la literatura como herramientas para revalorar lo mítico, denunciar los problemas sociales y la depredación de la Amazonía. Por último, somos conscientes de que Panaifo no es un caso aislado de la Amazonía, pues los proyectos de nación se han enfocado de algún modo u otro en la inclusión del

9 Una genealogía más completa de la definición del intelectual se puede ver en Historia de los intelectuales en América Latina I y II, de Carlos Altamirano. 
mundo andino y se ha olvidado en muchos casos, por distintas razones, al mundo amazónico; sin embargo, esto ha motivado que los actores culturales de esta región desarrollen dinámicas y redes propias que esperamos se sigan dando a conocer.

\section{Conclusión general del dossier temático}

Los tres estudios que componen este dossier han procurado centrarse en las trayectorias y prácticas intelectuales de tres escritores de la Amazonía peruana, un espacio raramente convocado cuando se habla de una literatura nacional -sea como tema, sea como lugar de enunciación-, con el fin de visibilizar iniciativas de difusión cultural que se dieron desde el centro urbano de Iquitos para el conjunto de la región amazónica y el resto del Perú entre 1940 y 1980. Al estudiar los casos de Francisco Izquierdo Ríos, Javier Dávila Durand y Arnaldo Panaifo Teixeira hemos buscado destacar los puntos en común que supone llevar a cabo una actividad cultural e intelectual desde la Amazonía centrándose en temáticas vernáculas, como el hecho de no contar con mucha infraestructura de producción y difusión de la cultura escrita o el hecho que deban acumular varias funciones, como las de autor y editor, para llevar a cabo sus proyectos y adoptar soluciones originales acordes con el medio y las circunstancias. A su vez, sus obras buscan recalcar la excepcionalidad del espacio amazónico y la riqueza de sus tradiciones orales indígenas desde el centro letrado de Iquitos. Dado que los tres casos de estudio siguen un orden cronológico, vemos los cambios de preocupaciones a medida que se vuelve más crítica la situación de la Amazonía con el modelo extractivista y la depredación del medio ambiente, que se fue acelerando con el auge del petróleo y 
el ultraliberalismo que caracterizó el final del periodo estudiado. El propósito del estudio comparativo no es fijar un arquetipo de lo que vendría a ser un intelectual de los centros urbanos amazónicos, pero la comparación es útil para dar cuenta de ciertas evoluciones. Así pues, si para alguien como Francisco Izquierdo Ríos la urgencia radicaba más bien en integrar la Amazonía a una noción de cultura peruana y por ello son fundamentales sus actividades desde el centro de decisión de políticas culturales nacionales que es Lima, Javier Dávila Durand construyó su carrera periodística desde Iquitos y se enfocó en la circulación de sus escritos, mientras que Arnaldo Panaifo se caracterizó más bien por una voluntad clara de descentralización y de reivindicación de lo estrictamente local a pesar de todas la dificultades que conlleva tal independencia. Por último, este dossier tenía también como objetivo revalorizar tres figuras de las letras amazónicas peruanas que han sido poco estudiadas desde una perspectiva global de sus quehaceres intelectuales, por lo que merecen ser rescatados.

Recibido: 10 de agosto del 2018.

Aprobado: 19 de diciembre del 2018.

\section{Bibliografía}

Albuquerque, G.

(2011) La trinchera letrada. Intelectuales latinoamericanos y Guerra Fría. Santiago: Ariadna Ediciones.

Arguedas, J. M., Izquierdo Ríos, F.

(1947) Mitos, leyendas y cuentos peruanos. Lima: Ministerio de Educación Pública. 
Ayarza Uyaco, A.

(2004) La literatura en la Amazonía peruana. Reflexiones y una propuesta de periodización. Kanatari (1050), 101-103.

Barclay, F. y Santos, F.

(1991) Poesía y narrativa amazónica. Iquitos: Oruga de Acción Cultural, COPAL.

Barcia Boniffatti, E.

(1942) La ciudad de Iquitos y la educación. Charla sustentada en la Asociación de Maestros Primarios. Trocha, 1 (6), 26-33.

Calvo Soriano, C.

(1976) 10 años de Proceso, 20 años de Javier. Proceso, mayojunio.

Calvo Soriano, C.

(1981) Las tres mitades de Ino Moxo. Iquitos: Proceso Editores.

Chávez Pastor, L.

(1958) La ermita de mis ensoñaciones. Iquitos: Imprenta Carranza.

Cornejo Chaparro, M.

(2013) Escribir en la frontera: un acercamiento a la obra de Francisco Izquierdo Ríos. En J. Vásquez Valcárcel, M. Cornejo Chaparro, C. Reyes Ramírez y G. Espino Relucé, Un río interminable de palabras: expresión literaria en la Amazonía peruana. Lima: s.n.

Dávila Durand, J.

(1957) Mis delirios. Iquitos: Imprenta Carranza.

Dávila Durand, J.

(1967) Yara. Iquitos: Editorial Jurídica.

Dávila Durand, J.

(1976) Los años son maravillosos. Proceso, 54-55.

El Diario de Marka (1980, 15 de julio). Se abrirán las puertas a la inquietud cultural del pueblo. Entrevista a Francisco Izquierdo Ríos. El diario de Marka. 
Estampa Revista de Expreso (1972, 9 de abril). Simplemente no he inventado nada. Entrevista a Francisco Izquierdo Ríos. Estampa Revista de Expreso.

Fiorucci, F. y Rodríguez, L. (Comps.).

(2018) Intelectuales de la educación y el Estado: maestros, médicos y arquitectos. Bernal: Universidad Nacional de Quilmes

Folklore. Tribuna del Pensamiento Peruano

(1943) Editorial. Folklore. Tribuna del Pensamiento Peruano, $2(4), 1$.

Gras, D.

(2009) Manuel Scorza y la internacionalización del mercado literario latinoamericano: del Patronato Del Libro Peruano a la organización continental de los festivales del libro (1956-1960). Alicante: Biblioteca Virtual Miguel de Cervantes.

Hernández, A.

Carta a Francisco Izquierdo Ríos del 10 de setiembre.

Hidalgo Morey, V. R.

(1958) Pan y fronda. Iquitos: Imprenta Carranza.

Hobsbawm, E. J. y Ranger, T. O. (Eds.)

(2012) L'invention de la tradition. París: Ed. Amsterdam.

Izquierdo Ríos, $\mathrm{F}$.

(1941) Carta a su esposa Olga Izquierdo del 16 de julio.

Izquierdo Ríos, F.

248 (1942) Los poetas y el río Amazonas. Trocha, 1 (5), 56.

Izquierdo Ríos, F. (

1964) Prólogo. En A. Hijar Soto, Folklore de las tres regiones. Lima: Imp. Rímac.

Izquierdo Ríos, F.

Pueblo y bosque: folklore amazónico. Lima: P. L. Villanueva. 
Kanatari

(1990) Forjadores de la cultura. Antología de la literatura regional. Kanatari (300), 13-39.

Lequerica Perea, G.

(1958) La búsqueda del alba. Iquitos: Imprenta Carranza.

Lequerica Perea, G., Linares, D., Hidalgo, V. R.

(1952) Selva lírica. Lima: Imprenta Abancay.

Marticorena, $M$.

(2009) De shamiros y decidores. Proceso de la literatura amazónica, de 1542 a 2009. Lima: Arteida.

Molina Campodónico, A.

(2011) Derroteros de la lírica loretana y la escritura poética de Ana Varela. Summa Humanitatis, 5 (2).

Molina Campodónico, A.

(2015) La búsqueda de una voz propia en la lírica loretana a partir de tres hitos sucesivos: Los primeros cantores de la Amazonia; Germán Lequerica y el Grupo Urcututu (Tesis para optar el grado de Magister en Literatura Hispanoamericana). Pontificia Universidad Católica del Perú, Lima.

Panaifo Teixeira, A.

(1982) El pescador de sueños.

Panaifo Teixeira, A.

(1986) El ocaso de Ulderico el multiforme. Iquitos: Municipalidad Provincial de Maynas.

Panaifo Teixeira, A.

Julia Zumba, la nodriza reina. Lima: Ironyodla Edi- 249 tores.

Pinilla, C. M. (Ed.).

(1999) Arguedas en familia. Lima: Fondo Editorial Pontificia Universidad Católica del Perú.

Ramírez, L. H.

(1958) Poemas de soledad y sombra. Iquitos: Imprenta Carranza. 
Trayectorias de intelectuales y redes culturales en la Amazonía peruana

entre 1940 y 1980

Remo

(1940) Presentación. Remo, 1 (1), 1.

Revista Peruana de Literatura

(2007) Loreto, un río de literatura. Revista Peruana de Literatura, 4 (6).

Rivera Cusicanqui, S.

(2015) Sociología de la imagen. Miradas ch ixi desde la historia andina. Buenos Aires: Tinta Limón.

Rumrrill, R.

(1965) Poesía de selva. Iquitos: Ediciones Rumrrill.

Rumrrill, R.

(1967)

Narradores de la selva. Iquitos: Editorial Jurídica.

Rumrrill, R.

(1971) Este hombre derrotó al cáncer. Trinchera (6).

Rumrrill, R.

(1973) Reportaje a la Amazonía. Lima: Ediciones Populares Selva.

Vidarte, G.

(2016)

Un nuevo imaginario para la Amazonía peruana: la práctica artística de César Calvo de Araújo y Antonio Wong (1940-1965) (Tesis para optar por el grado de Magíster en Historia del Arte). Pontificia Universidad Católica del Perú, Lima.

Westman

(1957) Saludo y evocación. Trocha. Tarapoto, año 1, número 1, p.3.

\section{Revistas:}

Bubinzana. Iquitos. (1965)

Los Shamiros Decidores. Iquitos. (1995-2013)

Proceso. Revista de la Amazonía para todo el Perú. Iquitos. (19661991)

Surcos. Iquitos. (1969) 
Trinchera. Iquitos. (1969-1971)

Trocha. Iquitos. (1941-1944).

\section{Archivos consultados:}

Archivo Francisco Izquierdo Ríos (archivo familiar)

Archivo Javier Dávila Durand (archivo familiar)

Archivo Arnaldo Panaido Teixeira (archivo familiar). 
